A

Aalberse R.C. Ábrahám C.S.

Abrahamsen T.G.

Abramov A.

Aceto G.

Acevedo C.

Acquila $\mathrm{M}$.

Adamovich $\mathrm{K}$.

Agbeko R.

Åhlman H.

Ahluwalia J.S.

Ahrens B.C.

Akbas L.

Aker A.

Akoyev Y.S.

Al-Bayaty $M$.

Al-Essa M.M.

Albrecht-Nebe $\mathrm{H}$.

Aldrich C.J.

Aldridge R.

Alfonso L.F.

Almaas R.

Almog S.

Altobelli E.

Altomare M.

Alvarez F.J.

Amato $\mathrm{S}$.

Amerongen G. van

Anagnostakou M.

Anastopoulou A.

Anatolitou $\mathrm{F}$.

Andersson U.

Andrews D.C.

Angulo A.F.

Anker J.N. van den

Anttila R.

Appel R.

Ariagno R.L.

Armbruster $\mathrm{M}$.

Armenio L.

Arnaiz A.

Arron G.

Arshad S.H.

Asensi M.

Ashton M.

Asperen R.M. van

Atalay A.

Azcona C.

Azzopardi D.
B

$\begin{aligned} 309 & \text { Bachmann D.C.G. } \\ 1,228 & \text { Badon T. } \\ 97 & \text { Baenziger O. } \\ 104 & \text { Baert M.R.M. } \\ 376 & \text { Bakke S. } \\ 290,355 & \text { Bakkeren J. } \\ 2,44 & \text { Balata A. }\end{aligned}$

200,223

212

92

3, 4 Bambang Oetomo S.

5, 180 Bamberger J.

14 Banovcin P.

14 Baoquan $\mathrm{Q}$.

207 Bar-Maor J.A.

306 Barber P.

109 Barnard M.

390 Barry J.

6 Barthelmes $\mathrm{H}$.

42, 134, 186 Bartmann P.

234 Baskin E.

7, 224 Basuyau J.P.

366 Batenburg J.J.

241 Bättig M.

376 Baudin J.

234 Bauer K.

164 Bauer P.

331 Baum J.D.

379 Bayaert C.

8 Beatty B.

347 Beaufort-Krol G.C.M.

321 Beaufort A.J. de

261 Bechensteen A.G.

337 Beck D.A.

9, 10, 329 Beck-Nenadov M.

11 Becker M.

363 Becker $\mathrm{K}$.

23 Beckh L.

386 Bedford Russell A.R.

308 Beek A. van der

234, 263, 290 Beigl M.

343 Beishuizen A.

314 Bel F. van

238 Bell J.

319 Belli D.

28, 29 Benders M.J.N.L.

227 Bentele K.H.P.

12 Bentley D.J.

91 Berger C.

Berger H.M.
Bergmann K.E.

Bergmann R.L.

Bergmann R.

Bernhard $W$.

Berni S.

Bernsau U.

Bernstein G.

Beyers N.

Beyers N.

Bialobrzeski B.

Biasini G.

Biasio P. De

Biban P.

Bicocchi P.

Bifano E.M.

Bijma A.

Billman D.

320

91

370

390

66,336

14,77

145, 146

258

235

107,220

15

309,312

208

352

23

16

133

17

18

18

31

151

214

19

218

95

20

33

$21,22,58,133$

91
55

$21,22,58,133$

358

306

165

133

Bishop N.J.

Blager F.B.

Börch $K$.

Bisgaard H. 264, 284, 292

24

Björksten B. 316, 323, 327

120

Blanco Quirós A. $\quad 307$

Blomquist H.K. $\quad 92$

Bocci V. 38

Boeri E. $\quad 164$

Boerlage A. 45, 47

Boersma R.E. $\quad 114$

Boesch Ch. 69

Boesch C. 192

Bogaard J.M. $\quad 302$

Bogers A.J.J.C. 365

Böhler T. 96

Böhm F. 239

Bohnen A.M. $\quad 346$

Bonati M. 144

Bonato M. 375

Böndi Z. 286

Bonsel G.J. $\quad 362,363$

Boot A.M. $\quad 30$

Bor M. van de $21,22,58,133$

25

Borelli D.A. 353

Bormann N. 67

Borressen A.L. $\quad 116$

Borthne K. 26

Bos A.F. 27, 28, 29

Bos E. 232

Bosma P.J. 254

Bossuyt P.M. $\quad 181$

Bouquet J. 30

Numerals refer to abstract number. 
Bowen B.

Brabäck L.

Bracci R.

Bragina N.K.

Braillon P.

Braithwaite S.

Brand R.

Brandenburg A.H.

Brandsma A.E.

Brandt E.

Braquet $P$.

Breier F.

Broek E. van den

Broerse H.M.

Bröker F.

Brösicke $\mathrm{H}$.

Brouwer A.

Brown G.

Brugman S.M.

Bruijnzeels M.A.

Bruin N.C. de

Brun N.C.

Brunelle Ph.

Brunetti L.

Brus F.

Bryant D.

Bucci G.

Bucher H.U.

Bühlmann U.

Buksh D.

Bull D.H.

Buonocore G.

Burgard P.

Burgio R.G.

Burgt I. van der

Butt W.W.

Buttenberg S.

Button B.M.

Bydder G.

\section{C}

Caballero M.D.G.

Cady E.

Caffarena P.E.

Cairns P.A.

Camargos P.A.M.

Campello M.J.

Campling G.

Canciani $\mathrm{M}$.

Cantürk N.Z.
109 Capodici I.

316, 323, 327 Caprino D.

38, 39 Cardinale F.

377 Carlini S.M.

63, 122 Carlsen K.H.

160 Carnielli V.P.

112, 236 Carratalá F.

333, 343 Carse E.

265 Casaer P.

369 Castro L.

1 Catalá J.

393 Catto-Smith A.G.

266 Ceravolo R.

329 Cernerud L.

293 Chambon M.

31 Chan V.

115 Charlton M.

42, 134 Chiarelli F.

120 Chlopicka J.

242, 345, Christodoulou M.

346,397

32,33

34

145,146

308

35,36

91

185

$13,37,209$

235

341,342

23

$38,39,40$

191,386

384

378

359

41, 267 Cortés E.

91 Cosco C.

Costa E.

Costa R.

Costeloe K.L.

$42,134,186$

Counsell $\mathrm{C}$.

Cowan D.

Craig N.

Crawford C.

Creuwels L.A.J.M.

Crisarà $\mathrm{D}$.

Cristea A.

Cuccurullo $\mathrm{O}$.
185 Culler F.L.

2, 44 Cunningham S.

308 Cunsolo C. Lo

334 Curcin $\mathrm{O}$.

271, 289, 322 Curstedt T.

$45,46,47$ Curzi-Dascalova L.

48, 49 Cutz E.

50

259

12

238

41,267

354

61

122

276

50

$132,240,241$

189

379 .

272

295

319

288

51,122

93

353

109

63

308

245

176

108

71

52

42,134

53

360

49,167

353

23

354

171

173,174

161

333

304

54

354

175

354

\section{D}

D'Antona D.

D'Antonio E.

D'Eugenio D.B.

Dalt L. Da

Damerow T.

Dani M.

Dannemann A.

Daugbjerg P.

David L.

David-Cu R.

Davies E.G.

Dawani N.M.H.

Dawson A.

Dayer Pastore F.

Dean T.

Deehan A.

Degenhart H.J.

Deinum H.T.

Delivoria-Papadopoulos M.

Delpy D.T.

Demel R.A.

Derganc $M$.

Derksen-Lubsen G.

Derkx H.H.F.

Deshpande S.A.

Destrée-Vonk A.

Deufel $T$.

Devin S.

Devlieger $\mathrm{H}$.

Diamanti E.

Diankova D.N.

Dieckmann A.

Diependale J.F.

Dietz V.

Díez-Pardo J.A.

Dinger J.

Dios J. de

Dixon S.

Döbeln U. von

Dobosz P.

Dodero P.
166

155

44

213

99,162

272

283

6

132

86

360

273

159

309

292

63

248

19

255

249

55

319

383

$32,33,45,47,56$

130

$79,82,83$

6,134

54

361

62, 181

396

57

123

111, 150

319

259

215

295

15

287

209

234

229

167

249

92

189

164 


\section{AUTHOR INDEX}

\begin{tabular}{|c|c|c|c|c|c|}
\hline Does E. van der & 345 & $\mathbf{F}$ & & Gamba G. La & 144 \\
\hline Dolezel Z. & 177 & & 392 & Ganga S. & 124 \\
\hline Dolovich M.B. & 109 & $\begin{array}{l}\text { Faber Y.A. } \\
\text { Fan L. }\end{array}$ & 120 & Garcia G. & 184 \\
\hline Domizio S. & 380 & $\begin{array}{l}\text { Fan L. } \\
\text { Fanariotis D. }\end{array}$ & $\begin{array}{l}120 \\
347\end{array}$ & García-Foncillas J. & 12 \\
\hline Donahoe P.K. & 135 & & $\begin{array}{l}347 \\
393\end{array}$ & Garcia-Hernández G. & 275,291 \\
\hline Donald P.R. 274,3 & $30,334,344$ & $\begin{array}{l}\text { Fang-Kircher S.G. } \\
\text { Farah G. }\end{array}$ & $\begin{array}{r}393 \\
59\end{array}$ & Garcia-Sala F. & 238 \\
\hline Dongen J.J.M. van & 20,245 & $\begin{array}{l}\text { Farah G. } \\
\text { Farnetani M.A. }\end{array}$ & $\begin{array}{l}59 \\
40\end{array}$ & Garrouche A. & 299 \\
\hline Doria $\mathrm{M}$. & 360 & $\begin{array}{l}\text { etani IV.A. } \\
\text { er J. }\end{array}$ & 63 & Gastiasoro E. & 234 \\
\hline Dörner $\mathrm{K}$. & 210 & Fegert J.M. & 64 & Gaustad P. & 97 \\
\hline Dorrepaal C.A. & 58 & Ferdousi H.A. & 310,311 & Geesink B.J. & 133 \\
\hline Dorsch $W$. & 312 & Ferrali M. & $\begin{array}{r}310,011 \\
39\end{array}$ & Gekova N.G. & 295 \\
\hline Doulgeraki $\mathrm{K}$. & 347 & Ferreira C.S. & 268,269 & Gellén B. & 1 \\
\hline Dousset $B$. & 352 & Ferrer E. & 49 & Gemke R.J.B.J. & 362,363 \\
\hline Dragas A.Z. & 361 & Festen $C$. & 128 & Genderingen H.R. van & 72,73 \\
\hline Dreborg S.K.G. & 310,311 & Ficuccilli F. & 185 & Gerdin B. & 205 \\
\hline Dresler $\mathrm{M}$. & 177 & o M. De & 38 & Geven-Boere L.M. & 237 \\
\hline Drop S.L.S. & 56 & Fiorenza M.L. & $\begin{array}{r}50 \\
185\end{array}$ & Gevers $\mathrm{M}$. & 72,73 \\
\hline Drossou V. & 59 & Fiorucci P. & 185 & al $\mathrm{S}$. & 74,75 \\
\hline Dubos J.P. & 197 & r J. & 249.370 & Giannini L. & 185 \\
\hline Duc G. & $37,154,209$ & Fitzpatrick C. & $\begin{array}{r}249,3 / 0 \\
383\end{array}$ & Gie R.P. & 330,344 \\
\hline Dudenhausen J.W. & 142 & Fjaertoft G. & $\begin{array}{r}383 \\
65\end{array}$ & Gilbert $\mathrm{R}$. & 179 \\
\hline Duivenvoorden H.J. & 232 & Florescu P. & $\begin{array}{r}65 \\
175\end{array}$ & $\mathrm{D}$. & 38 \\
\hline Dumitru $\mathrm{I}$. & 175,176 & Fok T.F. & $\begin{array}{l}175 \\
109\end{array}$ & dano P. & 376 \\
\hline Dyduch A. & 305 & $\begin{array}{l}\text { FoK 1.t. } \\
\text { Fokker M.H. }\end{array}$ & $\begin{array}{l}109 \\
337\end{array}$ & Glastre C. & 63 \\
\hline Dzoljic-Danilovic G. & 266 & Foldenauer A. & $\begin{array}{r}337 \\
66\end{array}$ & Glinska A. & 189 \\
\hline & & Fon & 182,253 & Glorieux F. & 122 \\
\hline $\mathbf{E}$ & & Fontebasso P. & 380 & $\tan \mathrm{P}$. & 148 \\
\hline Economou E. & 143 & Fontes M.J.F. & 269 & $\operatorname{nan} P$. & 149 \\
\hline Edwards D. & 91,107 & Forster J. & $216,217,309$ & Gmyrek D. & 229 \\
\hline 134 & $8,149,158$ & & 312,335 & $\begin{array}{l}\text { n H.E. } \\
\text { ens W.H.F. }\end{array}$ & $\begin{array}{r}76 \\
10,338\end{array}$ \\
\hline Efstathopoulos T. & 143 & ard $\mathrm{T}$. & 65 & A.S. & 14,77 \\
\hline Egeler R.M. & 391 & Fourie P.R. & 67 & e L.M.G. van & 54 \\
\hline Eggermont E. & 259 & z I.D. & 23 & Z L. & 313,328 \\
\hline Eggert W. & 390 & est J. & 280 & S. & 307 \\
\hline Eken $\mathrm{P}$. & $60,81,244$ & Fretzayas A.M. & 211 & ers D. & 78 \\
\hline Eker E. & 277 & Frey U. & 117 & acher A. & 339 \\
\hline Elton R. & 155 & Frischer $\mathrm{T}$. & 216 & González-Caballero D. & 275 \\
\hline Enander I. & 310,311 & Fritz K.I. & 83 & ud J.M. & 79 \\
\hline Engelhard C.F. & 392 & ld A.H. & 271 & Gordon-Smith E.C. & 19 \\
\hline Ens-Dokkum M.H. & 236 & K.H. & 139 & her L. 80, 336, & 364,369 \\
\hline Eriksen $\mathrm{M}$. & 350 & Funck G. & 214 & Goto $\mathrm{M}$. & 256 \\
\hline Eriksson $\mathrm{M}$. & 61 & Fünders B. & 252 & Goudoever J.B. van & 47 \\
\hline Eriksson L. & 205 & Fuong R. & 166 & n J.B. & 165 \\
\hline Erol $\mathrm{N}$. & 381 & Fusch Ch. & $68,69,70$ & Graaf Y. van der & 60 \\
\hline Esch A. van & 62 & & & Greenough A. & 276 \\
\hline Esser G. & 386 & $\mathbf{G}$ & & Gregori B. & 46 \\
\hline Eudoridou I. & 59 & di L. & 71 & Greiner B. & 367 \\
\hline Ewald U & 65,225 & n R.E. & 139,140 & Greisen $\mathrm{G}$. & 25,34 \\
\hline & & Gaillard J.L.J. & 282 & Groenendaal F. & 81,82, \\
\hline & & $\mathrm{Ga}$ & 167 & & 83,244 \\
\hline
\end{tabular}


Grond J. van der

Groot L. de

Groot R. de

Gross S.J.

Grünberg K.

Gubina $M$.

Gugler E.

Guillén J.J.

Gültekin A.

Günther A.

Gupta S

Gürdal A.

Güsewell Y.

Gustafsson J.

Guthmann F.

Gysel D. van

Gyurasics A.G.

Gyurkovits K.

\section{$\mathbf{H}$}

Haagsman H.P.

Haaland $\mathrm{K}$.

Habbema D.J.

Hachimi-Idrissi S.

Hack W.W.

Hadjistamatiou Z.

Hågå $P$.

Hagenfeldt L.

Hählen $\mathrm{K}$.

Hahn T.

Hakanson D.O.

Håkansson L.

Hakim E.A.

Hales C.N.

Halila R.

Hall A.

Hall $M$.

Hällgren R.

Halvorsen $\mathrm{R}$.

Hammerman C.

Hannam S.

Hanrahan D.

Hansen G.

Hardt $H$. von der

Harms E.

Harvey D.

Hasan M.

Haschke F.

Hasri B.S.
81 Hatzinicholas N.

84 Hauck W.

$10,245,317$,

$329,337,338$

85,86

218

361

235

320

77

142

246

277

262

225

219

394

246

286

54

87,88

62

89

72,73

143

26

92

20,391

101

86

65

314

93

201

173, 174

319

205

289,322

104

90

91

297

262,263 ,

$280,290,355$

111,150

160

341,342

190

119

Haverkorn C.

Hawdon J.M.

Hayes M.

Hayouni A.

Heijmans H.S.A.

Heijnen C.J.

Heimler R.

Heine R.G.

Heineman E.

Heldin E.

Heldt G.P.

Helge $\mathrm{H}$.

Hellwege H.H.

Helwig J.J.

Henriksen $\mathrm{O}$.

Henschen M.

Hentschel U.

Hentschel R.

Hermans N.A.

Hermans P.W.M.

Herschkowitz N.

Heuston C.

Heykamp A.

Hide D.W.

Hieronimi G.

Higgenbottam $T$.

Hill A.

Hingre R.V.

Hirasing R.A.

Hoch B.R.

Hoffman D.J.

Hoffman G.L.

Hoffmann G.F.

Hogåsen A.K.M.

Holland W.P.

Holm N.R.

Hoog A.I. van 't

Hooijkaas $\mathrm{H}$.

Hop W.C.J.

Horal M.

Horber F.

Hornakova A.
Have-Opbroek A.W ten 265

Heijden R.W.J. van der

Hertzberger-ten Cate R.

Heuvel M.M. van den

$95,96,151,152$

Hofstee-Hooftman T.W.A. 265

Hoogenboezem $\mathrm{T}$.

Horst C.M.A.M. van der

301

257

265

92

93

50

299

331

237

105

203

41,267

126

102

23

31

336

260

125

216

70

278

123

338

192

373

50

337

35

314

336

4

139,140

86

239

94,279

82

23

23

265

97

300

315

338

56,338

$293,302,329$

98

68

99

Numerals refer to abstract number.
Hörsten B. von 280

Houdkamp E. $\quad 58$

Houmes R.J.M. $\quad 78$

Howell J.H. $\quad 120$

Hoy T. 249, 370

Huang C.C. $\quad 79$

Huisman M. 114

Huisman-de Boer J.J. $\quad 10$

Husby S. $\quad 315$

Huth R. $\quad 371,372$

\section{I}

Iasonni $\mathrm{V}$.

164

IJsseldijk A. van 9

IJsselstijn $H . \quad 258,281,282,283$

Ikonen R.S. $\quad 137$

Iles R. 100

Ingram D.M. $\quad 90$

Ipsiroglu O.S. $\quad 101$

Ismail S. $\quad 249$

Iversen L. $\quad 348$

Ivkovic D. 196

J

Jacobsen L. $\quad 310,311$

Jaeken J. 259

Jaggi J. 13

Jakobs C. 202, 231

Janecke A.

Jansen G.H.

96

Jansons R.A. $\quad 166$

Jarenwattananon M. 203, 204

Järvenpää A.L. 243

Jarvis M. 93

Jasi ska A. $\quad 116$

Jenkins J. 43

Jenkins S.G. $\quad 340$

Jenni $O$. 37

Jensen E. $\quad 68$

Jerray M. 299

Jiménez M. 12

Johnson B. 61

Johnson P. 261

Johnsson $H$. 102, 205

Jones R.C. 135

Jones J.G. 249, 370

Jong $W$. de 212

Jongste J.C. de 266, 281,

$282,293,300,302$

Jonzon A.

131,205 


\section{AUTHOR INDEX}

Jorch G.

Jordana $M$.

Josties $\mathrm{C}$.

Julge $\mathrm{K}$.

Jüngst $\mathrm{B}-\mathrm{K}$.

Jurecka W.

Juste $M$.

$\mathbf{K}$

Kaempf D.E

Kaplan M.

Kardos G.

Karpouzas J.G.

Kaufmann R.

Kavelaars A.

Keel M.

Kelmanson I.A.

Kemal Topaloglu A.

Kerrebijn K.F.

Kesall A.

Kind $C$.

Kirkbride V.

Kirkbride V.

Kirpalani H.M.

Kiselevich O.

Kivivuori S.M.

Klaessens J.H.

Kleemann W.

Klug B.H.

Knapp K.

Knutsson A.

Koch H.G.

Kofstad J.

Kohnle I.

Kok J.H.

Kolleck I.

Kollée L.A.

Kollmann M.

Koltai M.

Koning $\mathrm{H}$.

Koningsbruggen S. van

Konopleva T.N.

Konstantinos R.

Koolen A.

Koopman-Esseboom C.

Koorevaar R.Th.

Koppens P.F.J.

Koster M.

Kostyk E.

Koukoutsakis P.M.

Koumentakou I.

$\begin{aligned} \text { 101, 278, } 336 & \text { Kovács J. } \\ 108 & \text { Kraemer R. } \\ 309 & \text { Kraker J. de } \\ 316,323,327 & \text { Krämer W. } \\ 371 & \text { Krauze M. } \\ 393 & \text { Krebs H. } \\ 167 & \text { Kreis R. }\end{aligned}$

Kremenopoulos G.

Kreth H.W.

Krob G.

103

104

374

301

368

105

37,209

349

256

302

4

Krosniak M.

Krzywiecki A.

Kuehr J.

Kühl P.G.

Kühni C.E.

Kuhnle U.

Kuipers J.R.G 16

Kulik W.

Kutscha A.

Kyrvasilis $F$.

106

42

$107,134,220$

108, 109

326

110

127,128

356

284

183

$316,323,327$

$111,163,252$

87

213

112,250

219

127,128

210

1

317

213

113

290

212

L

Lachmann B.

Lack G.

Lafeber H.N.

Lakeman I.E.A.

Laki I.

Lamminranta S.

Lampe F.

Lanciotti M.

Langslet A.

Lapillonne A.

Last B.F.

Latimer $R$.

Laurent T.C.

Laurenti $F$.

Lawrey S.

Lazar I.

Leclerc F.

Leegaard J.

Leichsenring $\mathrm{M}$.

Leighton J.O.

Lekic V.

León P.

114, 115 Lequien P.

345 Leroy $\mathrm{M}$.

56 Leth $\mathrm{H}$.

9 Liefaard G.

116 Liem K.D.

211 Lifshitz M.

347 Lijster-de Raadt J.
228 Linder N.M.

129

117, 235, 251 Linderkamp O. 96, 178, 193, 198,

391

118

226

312

69,192

59,215

324

119

189

305

216,325

363

285

119

231

95,191

301

301

Lingen R.A.van

$199,213,214,367$

Lipp A.

130

Lippold R.

13

Lipsou N.

118

379

288

Little S.A.

318,319

Lituania $\mathrm{M}$.

44

Liubsys A.

131

Lo Cunsolo C.

2

Lobefalo L.

132

Lodrup Carlsen K.C. 289

Logier R.

$124,197,287$

Loon $\mathrm{T}$. van

332

Lopes Cardozo R.H.

133

Lopez S.L.

247,248

Lopez-Silvarrey A.

275,291

Lorek A.

$42,107,134$,

186,220

Lossius $\mathrm{K}$.

350

Losty P.

135

Lotgering F.K.

245

Lou $\mathrm{H}$.

125

Lozovskaja L.S.

113

181

Lubsen J.

24

Lucas A.

31

369

Ludwig A.

Luijendijk I.H.T.

45,47

Lukas W.

305

390

287

271

151

247

196

12

$124,197,287$

145, 146

125

30,126

127,128

366

394
136

339

137

38

179

100

Lundstrom K.E.

Lutsar I.

Luukkainen $P$.

Luzzi E.

Lynn R.

Lyon A.

\section{M}

Maalal K.

299

Maas Y.G.H.

138

Mac E.

184

MacDonald T.T.

171

Macnab A.J.

MacNamara J.J.

139, 140, 141

Magri M.

230

240

Mahmood N.

4

Maier R.F.

142

Maier $\mathrm{O}$. 


\section{AUTHOR INDEX}

Maio R.

Malamitsi-Puchner A.

Malashkin A.B.

Mallard C.

Mallet E.

Manca A.

Manganaro T.F.

Mannino F.L.

Marchal F.

Marchetti F.

Marchi A.G.

Marco A.G.

Marcos L.G.

Marcus C.

Marguet $C$.

Maric B.

Marín M.

Marinoni $\mathrm{M}$.

Markhorst D.G

Marks K.

Marquardt T.

Martin I.

Martin-Carrera I.

Martínez-Gimeno A.

Martínez A.

Martino D. Di

Martinot A.

Mastroni P.

Mastropasqua L.

Matthews S.

Matthews L.

Mattia D. De

Mattioli P.L.

Mauran $P$.

Maurer T.

Mayatepek E.

Mayer $\mathrm{H}$.

McClure G.

McColm J.

McCormick D.

McCracken G.H.

McGaw J.

McGowan J.E.

McIntosh N.

McIntosh N.

McLeod A.

McMaster D.

Meek J.

Megyeri P.

Mehmet $\mathrm{H}$.

Meijboom F.J.
353 Melegh B.

143 Meloni G.F.

296 Merwe J.P. van de

148, 149 Metodieva V.M.

145,146

308

135

23

352

144 Michel-Behnke I.

270 Michie C.A.

320 Midulla F.

320 Miert M.M.A.L.P. van

98 Miki M

145, 146 Milanesi O.

196 Milicevic J.

291 Milner A.D.

375 Milosavljevic S.

147 Minchinton A.I.

148, 149 Mino M.

150 Mirmiran M.

355 Mishra O.P.

263, 290 Mitkowska Z.

291 Mockridge J.N.A.

275 Moder B.

233 Modesto C.

287 Modi N.

53 Moen A.

132 Moene R.J.

314 Moison R.M.W.

314 Molenaar J.C.

376 Molinari A.C.

353, 354 Moller L.

165 Möller J.C.

180 Möller H.E.

151, 152 Möller J.C.

70 Molnár D.

43 Monaghan $\mathrm{H}$.

153 Monin P.

107 Monkman S.

334 Montalbetti M.

75 Moodley M.

83 Morales C.

100 Morava E.

$153,154,155,156$

173,174

43

107,220

157

158

232
Moren R.

Morgese G.

Mori P.G.

Morley R.

Morley C.J.

Morling N.

Moroz O.V.
159 Morse D.C.

115

53 Morville P.

165

373 Mosier H.D.

166

295 Moya M.

137 Muinck Keizer-Schrama

85 S.M.P.F. de

298 Muller A.

123 Müller $\mathrm{H}$.

101 Muller-Premru M.

372 Munte K.

$48,49,167$

351

185

281,282

103

360

196

90

196

139

103

138

82,83

189

3

361

321

161

162

147

133

126,283

164

348

80

163

364

159,228

383

352

109

375

140

13

159

243

$132,240,241$

$2,44,164,233$

24

3

315

296

Mupanemunda R.

Muramatsu K.

Muraskas J.

Murch S.H.

Muresan M.

Murray N.A.

Musialik E.

Musumeci F.

Mutch L.M.M.

Myers T.F.

Myhr T.L.

Myhr $\mathrm{T}$.

$\mathbf{N}$

Nakou S.

Nanulescu M.V.

Närska $M$.

175,176

Neff $M$.

339

Neijens H.J.

214

Nekvasil R.

317,329

Nel E.D.

177

Nelin L.D.

344

Nelle M.

Nemeth P.

Nespoli L.

Netzel M.

Neuber $K$.

Nicoll A.

Nicolopoulos D.

Niculescu F.

Nielsen K.G.

Niesters B.H.G.M.

Nieuwenhuizen $O$. van

Nishida S.

Nja F.

Nogales A.

Norset J.

Norsted T.

Nowak A.

Nowotny $T$.

203,204

178

203

375,384

364

355

179

143

175

292

337

60

230

271

291

322

131

189

180

Níguez J.C.

Numerals refer to abstract number.

320 
$\mathbf{O}$

O'Rahilly S.

Obladen $\mathrm{M}$.

Odino $\mathrm{S}$.

Oduro A.

Oei Y.B.

Oelert $\mathrm{H}$.

Oeseburg B.

Oeveren W. van

Offringa $\mathrm{M}$.

Ogihara $\mathrm{T}$.

Ohlsson A.

Okken A.

Oklek K.

Oldigs H.D.

Olinsky A.

Olivares A.

Olsen K.D.

Olsholt $\mathrm{K}$.

Olthof E.

Oosterkamp R.

Oranje A.P. $\quad 317,391,392,394$

Orderud W.

Orlova O.I.

Osnes J.B.

Osterhaus A.D.M.E.

Ostrea A.

Ostrea E.M.

Ouden J. den

Owen-Reece $\mathrm{H}$.

Oyasæter S.

Özkan G.

Özmen E.

Özmen M.

$\mathbf{P}$

Pabst M.J.

Pacheco B.A.

Pacis M.

Pap M.

Papoff P.

Partenadze A.N.

Pastuszko A.

Peart I.

Peckham C.

Peebles D.M.

Peeters E.

Peirano P.

Peitersen B.
Pekarak J.

Pelikh S.T.

Penková Z.

Penrice J.

Penrice J.M.

Penza R.

Penzien J.

Perenovska P.I.

Perisic V.

Peristeri J.

Perrin D.G.

Perticone F.

Pessenhofer $\mathrm{H}$.

Petersen $\mathrm{H}$.

Petko M.

Pettenazzo A.

Pettersen M.

Phelan P.D.

Phelan P.D.

Phillips N.

Photopoulos S.

Picaud J.C.

Picciolini E.

Pickering $\mathrm{M}$.

Pickett J.

Piersma A.H.

Pietrzyk J.J.

Pietsch M.

Pietschnig B.

Pietz J.

258

42,134

7

77

277

277

Pillwein K.

Pintér S.

Podlesny $\mathrm{T}$.

Poelen M.C.M.

Poets C.F.

Pohjavuori M.

Pohlandt F.

157 Pollak A.

135 Pöschl J.M.B.

184 Potapov A.S.

159 Praag M.C.G. van

185 Pracht $T$.

$207,222,377$

79

255

179

6,134

385

272

125

\author{
119 Q
}

194

177

$42,107,134,220$

Quak C.M.

130

Quint W.

337

186

376

192 Raap P.

80

295 Rademaker K.J. 81, 244

196 Radlovic N. 196

379 Raine J. 4

283 Raivio K.O. 129, 201

353, 354 Ramet J. 89

101 Rappe C. 190

315 Rascher W. 223

189 Rathore M.H. 340, 341, 342

360 Rating D. 96, 192, 213, 214

322 Ree R. van 309

267 Reeser M. 239

359 Reichelt K.L. 221

141 Reijngoud D.J. 29

347 Reiter H.L. 336

187, 188 Reitsma-Bierens W.W.C. 27

38 Rennie J.M. 4, 303

75 Reynolds E.O.R. 6, 42, 107,

$4 \quad 134,186,220$

265 Ridder M.A. de 114

116, 189 Riedel F. 273

252 Rigillo N. 308

190 Rigo J. 187, 188

95, 191, 192, Rigó L. 286

213, 214, 386 Riikjärv M.A. 316, 323, 327

393 Riol M. 12

1 Riou Y. 124, 197, 287

226 Robben S. 293

331, 332 Roberts I. 148, 149, 172

355, 356 Robertson B. 99, 162

243 Rochat T. 55

66, 229 Roelandt J.R. $\quad 232$

101 Rogers L.K. 246

193 Rognum T.O. 221, 357

194 Roksund O. 271

392 Roland E.H. 139, 140

216 Romantsov M.G. 296

195 Rootwelt T. 7, 162

28, 138 Rosgilly L. $\quad 52$

161 Ross P. 100

125 Rossi K. 46

353, 354 Rotenberg M. 366

187 Roth S. 107, 134

Rothbarth Ph.H. 337, 333,

343 
Rothuis E.

Rousseau S.

Rudolph A.

Ruef P.

Rupp A.

Ruppers F.

Rus H.G.

Rusconi F.

Rüstow $B$.

Ruys J.H.

Ryan M.L.

\section{$S$}

Sabatino G.

Saksela M.

Saleri V.

Salle B.L.

Salo M.K.

Samsom J.F.

Santachiara P.

Sarafidis K.

Sarafidou E.

Sarakutsa A.V.

Sargentini I.

Sargentoni J.

Sarnesto A.

Sasidharan P.

Sastre J.

Sauer P.J.J.

Saugstad O.D.

Savasir I.

Savelkoul H.F.J.

Schaaf H.S.

Schaible T.

Schalk-van der Weide Y. 298

Schaub J.

Scheffers E.C.

Scheid A.

Schettini F.

Schlaud M.

Schlegel-Haueter E.

Schmid V.

Schmidt $H$.

Schmidt E.

Schnauffer M.

Schnitzer J.J.

Schoemaker R.C.

Schoeman J.F.

Scholte B.J.
147

124,197

355,356

198,199

191

200

175

71

219

236

182,253

380

201

183

$51,122,187$

137

202

233

215

8.

377

39

91

129

203, 204

238

$9,45,47$,

$114,115,258$

$7,99,162$,

$221,224,357$

381,382

317

$274,330,344$

364

298

282

206

376

356

55

325

191

312

193

135

10,329

334

254
Schranz D.

Schreuder A.M.

Schröder W.

Schuierer G.

Schullenberg E.

Schulte S.

Schultz K.

Schulz J.

Schuster E.

Schuster A.

Schuster V.H.

Schwarz U.

Scott F.

Scuderi $F$.

Sedin G.

Seear M.

Segerer H.

Seidenberg J.

Seidenspinner S.

Sennhauser F.H.

Senterre J.

Seppel C.K.

Sevastiadou S.

Sezgin N.

Shahak E.

Shanbhogue L.K.R.

Sharipov R.H.

Shield J.P.H.

Siebenthal K. von

Sierrasesúmaga L.

Sievers E.

Siimes M.A.

Sillevis Smitt J.H.

Silverman E.D.

Sima D.

Simeoni U.

Sinaasappel $\mathrm{M}$.

Sinaniotis C.A

Singh S.K.

Siphanto $W$.

Sirimanne E.

Siverman $M$.

Skomedal $\mathrm{T}$.

Skov M.

Skov R.

Slijper F.M.E.

Sluiter W.

Sluyter $M$.

Smeets H.J.M.

Smeets D.

Smeulders M.
371, 372 Smid G.B. $\quad 16$

236 Smirnov A. $\quad 387$

123 Smith J. 67

163 Smith M. $\quad 140$

160 Smith C.V. 246

94, 279 Smrkovsky M. 237

228 Smuts N.A. 330, 344

64, 309 Snellman K. $\quad 92$

190 Sobotka-Plojhar M.A. $\quad 147$

297 Sofer S. 366

324 Sola A. 23

364 Soletta G. $\quad 53$

344 Solís P. 307

233 Sontheimer D. 213, 214

102, 131, 154, 205 Soubasi V. 215

139 Souza P. de 370

206 Spanos Th. 379

280 Spassov L. 272

324 Spee-van der Wekke J. 298

285 Spencer J.A.D. 6

187, 188 Spiekerkötter E.F. 216

152 Spuls Ph.I. 396

143 Spürgin P. 217

381, 382 Squier M.V. 158

366 Stadler B.M. 235

30 Stam H. 218

207 Starre C. van der 293

208 Steck J. 101

37, 209 Steensel-Moll H.A. van 62,

$12 \quad 337,343$

210 Stellaard F. 202

11,110 Stellin G. $\quad 360$

391, 396 Steneroth G. $\quad 61$

321 Stepakina N.I. 222

390 Stephan V. 325

260 Stevens P. 219

254 Stevens M. 314

211 Stewart A.L. 107, 220

365 Steyerberg E.W. 62

365 Stoltenberg L. 221, 224, 357

148,149 Stopfkuchen $\mathrm{H}$. 118

169 Stores G. 304, 387

26 Storm H. 221

292 Storme L. 124, 197, 287

315 Stravrinadis C.S. 211

121 Streckert H.J. 312, 335

281 Struycken V.H.J. 266

338 Strzelecki T. 189

56 Stuart A.G. 370

378 Studenikin V.M. 207,

$212 \quad 222,377$ 


\section{AUTHOR INDEX}

Stute $\mathrm{H}$.

Suehiro G.

Suehiro A.

Suijlekom-Smit L.W.A. van $242,345,373,397$

Sulkers E.J.

Sulyok E.

Sundar T.B.

Sunehag A.

Suska A.

Suter S.

Suur M.H.

Sweed Y.

Swietlinski J.

Szczerbinski T.

Szücs G.

T

Tabka Z

Tacke U.

299

Taets van Am

Takei Y.

Takens J.

Tang W.

Tanman Ç.

Tannenbaum $\mathrm{L}$.

Tanzer F.N.

Tarrade $\mathrm{T}$.

Taylor C.J.

Tegtmeyer F.K

Teianu $\mathrm{M}$.

Teller $W$.

Tellería J.J.

Temesvári $\mathrm{P}$.

Thomas L.

Thome U.

Thomson L.

Thomson A.

Thoresen $\mathrm{M}$.

Tibboel D.

Tiddens H.A.W.M.

$281,282,283$

266,300
266

Timmers-Reker A.J.M. 254

Tinsley L.R.

Tinsley C.H.

Toft P.B.

Tognoni G.

Toledo-Eppinga L. van

Tomasini B.

288

200

64,312

161

277

183

227

1

74,75

252
80,369

175,176

66

307

1,228

91

229

173,174

261,304

87,88

231

39
367 Toorenenbergen A.W. van 394

230 Topa M.

230 Töpfer A

Torubarova N.A.

Tosev O.

47 Touwen B.C.L.

223 Tovar J.A.

224 Townsend J.

225 Trevett D.

278 Troche B.I.

55 Truffert P.

337 Tsakiris D.

368 Tsanakas J.N.

226 Tsantali C.

\section{Uj M.}

Ulanova M.A.

Ullrich $\mathrm{K}$.

Ungerstedt $\mathrm{U}$

Utens E.M.W.J.

$111,150,163,252$

UytdeHaag F.G.C.M

Uzunsel $\mathrm{S}$.

V

Vaandrager G.J.

Vágvölgyi J.

Valbuena $\mathrm{C}$.

Valetto A.

Valls-Soler A.

Vasar M.

Vassella C.C.

Vecchio G.C. Del

Vecht-van den Bergh R.

Veen $S$.

Veer E. van der

Veerman A.J.P.

Vege $\AA$.

Velden $K$. van der

Velden $T$. van de

Velthoven C.A.M. van

Ven-Daane I. van der

Venge $P$.

Vento $M$.

Verberne A.A.P.H.

Verbrugh H.S.

Verhoef A.

Verhoeven M.A.J.

Verhulst F.C.

107,220

249,370

124,197

94, 326

331,332

Verloove-Vanhorick S.P. 112, 236,

Numerals refer to abstract number. 239
176

229

377

196

237

234

23

215

301

215

200

98

232

227

Vermathen $P$.

163

Vermeijden I. 394

Verri A. 384

Verrotti A. 132, 240, 241, 380

Versmold $\mathrm{H}$. $\quad 15,336$

Versprille A. 218

Verstappen-Dumoulin B.M.A.A.

Versteeg S. $\quad 245$

Verwey R.A. 236

Viinikka L. $\quad 110$

Vijlbrief L.S. $\quad 242$

Vijlder J.J.M. de 250

Villa-Asensi J.R. $\quad 275,291$

Viña $]$.

Virkola K.

238

243

Virtanen M.K.G. 243

Visser G.H.A. $\quad 96,105$

Visser H.K.A. 32, 33

Vogel M. 10

Volbracht A. 278

Voßbeck S. $\quad 66$

Vries L.S. de 60, 81

Vries T.W. de 237

Vries L. de 244

Vries E. de 245

Vught A.J. van 362,363

Vujnovic Z. $\quad 196$

307

233

234

W

Waal W.J. de 121

Waal Malefijt R. de $\quad 317$

Wabitsch M. $\quad 70$

Wafelman L.S. $\quad 246$

Wagner M. 206

Wahn U. $\quad 64,309,312$

Wahn V. 297, 325

Wales J.H.K. $\quad 75$

Walter M. 217

Walther F.J. $\quad 247,248$

Ward Platt M.P. $\quad 57$

Wardrop C.A.J. $\quad 249,370$

Wareham P. 52

Warner J.O. $\quad 318,319$

Wassenaer A.G. van 250

Watkinson M. 389

Wattimena D.J.L. $\quad 45$

Wauer R.R. $\quad 5,180$

Weder M. 251

Weemaes C.M.R. $\quad 378$

Weglage J. 252 


\section{AUTHOR INDEX}

Weindling A.M.

Weir F.

Weisglas-Kuperus N. 114, 115

Weller E.

Wensly D.F.

Werchau $\mathrm{H}$.

Wering E.R. van

Wessels J.

Westerhof $\mathrm{N}$.

Wheater $\mathrm{M}$.

Wiberg K.

Wieckiewicz J.

Wigglesworth J.

Wiggs L.

Wijs I.J. de

Wilke $\mathrm{M}$.

Williams C.

Wilson D.C.

Wippermann C-F.

Wissel $\mathrm{H}$.

Witsenberg M.

Woestenborghs R.

Wolf $\mathrm{M}$.
255 Worgall S.

253

80

141 Wrzosek W.

312, 335 Wu L.L.

20 Wulbrand $\mathrm{H}$.

67 Wyatt J.

72 Wylezinska M.

303 Wynn R.

190

$116 \mathbf{X}$

168 Xanthou $\mathrm{M}$.

304, 387

56

254

148, 149 Yalman Y.

43 Yap L.

371, 372 Yartsev M.N.

219 Yonetani M.

365 Yoxall C.W.

9 Yu V.

37, 209 Yue X.
223

242, 345,

346,397

339

189

119

358

$6,42,134,186,220$

$42,134,186$

249

Zacchello F.

Zachwiejowa Z.

Zani S.

Zebidi A.

Zegers B.J.M.

Zeller W.P.

Zetterström R.

Zhu A.

Zijlstra W.G.

Zijlstra J.

Zilow E.P.

Zilow G.

Zimmer P.

Zimmermann $\mathrm{H}$.

46,360

189

39

299

105

256

61

83

16

105

347,379

14 Zimmermann L.J.I.

182 Ziora D.

313, 328 Ziora K.

Zubrod C.

255 Zwet J.M.L. van

Zygulska-Machowa $\mathrm{H}$.
257
257

150

76

258,259

305

305

297

260

116 


\title{
Subject Index to Abstracts
}

\author{
(Numbers cited refer to abstract numbers)
}

Abdominal pain, recurrent, prevalence and relation to psychological cause, children, 306

Absorptiometry

dual energy $x$-ray

reliability of determination of wholebody composition, term and preterm infants, 188

role, assessing bone mineral content and body composition, VLBW infants, 122

Absorption, carbohydrate and fat, after bowel resection, neonate, 126

Abstracts

assessment and objectivity of, 156

structured versus unstructured, information content comparison, 154

Academic achievement, short-stature children, after intrauterine growth retardation, 121

Acanthocytosis, with Hallervorden-Spatz disease, electron spin resonance study of erythrocyte cell membranes, children, 40

Acetaminophen, rectally administered, pharmacokinetics and dynamics, preterm infants, 130

$\mathrm{N}$-Acetylaspartate, and cerebral lactate ratios, after hypoxia-ischemia, newborn piglet, 134

N-Acetylcysteine, stimulating lung hyaluronan synthesis, 102

Adenovirus infection, nosocomial transmission of, neonates, 200

Adherence, clinical significance of testing for, in coagulase negative Staphylococci, neonates, 361

Adhesion, Streptococcus pneumoniae, to human epithelial cells, 338

Adipose tissue, fat composition of, ${ }^{13} \mathrm{C}$ MRS role in measuring, infants, 91

Adolescent

acute respiratory problems, life-style and activity patterns comparison study, 8

atopic sensitization prevalence in Estonia, 323

cystic fibrosis, positive expiratory pressure, gastro-esophageal reflux symptoms during chest physiotherapy, 267

IDDM

onset mortality rates, 239

pancreas size, ultrasound evaluation, 241

impetigo, occurrence and treatment of 397

inflammatory bowel disease, growth failure and malnutrition, 30

juvenile chronic arthritis, psychosocial functioning, 383

lactose intolerant, yogurt in diet, 196

lung function, healthy males, outdoor air pollution effects, 320

males, serum transferrin levels, indicator of iron deficiency or erythropoiesis, 11

obese, body composition changes during weight reduction, deuterium dilution measurement, 70
Adrenaline, nebulized, budesonide and, treatment for croup, comparison study, 301 Adrenoceptor, $\alpha$ and $\beta$ relationship, effects on myocardial function, 26

Airway

contraction, isobaric, new device to measure, 300

disease, lower, tidal flow volume changes, eosinophil cationic protein and myeloperoxidase, children, 289

obstruction, upper, lung function testing in, and flexible bronchoscopy, preterm and term infants, 5

Albumin levels, malnourished children, 227

Alcohol, use during pregnancy, meconium analysis role in determining, 184

Allergen

allergic sensitization to, prevalence of, at four years of age, 314

bronchopulmonary aspergillosis, diagnosis in cystic fibrosis patients, 318

disease, qualitative and quantitative differences in immune system, children, 317

dust mite, HLA-class II molecule relevance in immune response, children, 325

sensitization

and disorders, prevalence of, to common allergens, at 4 years of age, 314

influence by respiratory syncytial virus infection, infants, 312

prevalence of, Estonian adolescents, 323

Allergy, development of, in relation to nutritional allergen challenge and infectious diseases, infants, 235

ALTE. see Life threatening episodes, acute

Aluminum contamination of intravenous feeding solutions, effects on long-term developmental outcome, preterm infants, 24

Alveolar-arterial gradient, differentiating between asthma and vocal cord dysfunction, children, 120

Alveolar-arterial oxygen difference and ratio, ventilated neonates, 71

Alveolar volume, reduced, pulmonary diffusing capacity, children and adolescents, 218

Amino acid, levels, after dexamethasone treatment, preterm infants with bronchopulmonary dysplasia, 29

Amoxicillin, pharmacokinetics of, preterm infant, 10

Amphetamine abuse, during pregnancy, follow-up of children after 14 years, 61

Analgesics, acetaminophen, pharmacokinetics and dynamics of, preterm infants, 130

Anastomosis, bidirectional cavopulmonary, postoperative management, continuous $\mathrm{O}_{2}$ saturation monitoring, in inferior caval vein, 365

Anemia

acute infection role in causing, prevalence, infancy and childhood, 77

chemotherapy-induced, recombinant hu$80 \mathrm{~A}$ man erythropoietin treatment for, children with cancer, 18

erythrocyte volume, flow cytometry role in determining, fetus and infant, 249

plasma lactate as indicator of, piglet, 87

of prematurity

blood transfusion effects on apnea, bradycardia, tachycardia, and oxygen saturation, 367

recombinant human erythropoietin treatment, nutrition effects on effectiveness of, 17

timing of EPO administration, preterm infants, 215

Anemia/hypovolemia, cause of impaired oxygen transport, after cardiac surgery, 370

Angiography, determining precerebral and cerebral vessel anatomy, newborn piglet, 88

Angiotensin II, and nitric oxide interaction, vascular responses in kidney, rabbit, 260

Ankara Developmental Screening Inventory, and its environmental correlates, assessing development, children, 381

Anorexia, children with cancer, megestrol effects on, 12

Anthropometry, nutritional assessment, infants, 33

Antibiotics

amoxicillin pharmacokinetics, preterm infant, 10

intravenous, effects on lung functions and inflammatory markers in bronchial secretions, cystic fibrosis patients, 55

Antibodies

antineutrophil cytoplasmic, in idiopathic pulmonary hemosiderosis, children, 307

maternally derived, decay of, respiratory syncytial virus, neonates and infants, 333

Anti-epileptic therapy, causing behavior disturbances, children, 380

Antioxidant

administration, preventing birth-associated fetal oxidative stress, neonatal rat 238

status, inhaled nitric oxide effects on, lamb, 133

and surfactant liposomes, protecting against oxidant stress, preterm rabbits, 248

Antipyretics, treatment for febrile seizures, children, 62

Aortopulmonary shunt, metabolic response to exercise, lambs, 16

Apnea

blood transfusion effects on, preterm infants, 367

body position influence on, preterm infants, 118

EEG-suppression after augmented breaths during, preterm infants, 358

head elevated prone position during nurs- 
ing effects on incidence of, preterm infants, 37

increased incidence, after prenatal exposure to cocaine, 203

laryngeal chemoreflex, naloxone treatment for, piglet, 221

obstructive sleep, children with craniofacial anomalies, 94

Apoptosis, increased in brain after hypoxiaischemia, newborn piglet, 158

ARDS. see Respiratory distress syndrome, adult

Arterial oxygenation, exogenous surfactant and nitric oxide as treatment for, 78

Arteriosus, patent ductus, bisferiens pressure peaks in neonatal radial artery wave as indicator of, 72

Artery, radial, wave, bisferiens pressure peaks in, as indicator of patent ductus arteriosus, neonate, 72

Arthritis, juvenile

chronic, psychosocial functioning in children with, 383

rheumatoid, cytokine production by MNC from synovial fluid, 321

Aseptic meningitis, interleukin-6 levels in cerebrospinal fluid, 339

Asphyxia

brain abnormalities after, ${ }^{1} \mathrm{H}$ magnetic resonance spectroscopy, infant, 186

glucose administration after, effects, hyperinsulinism with bilateral pneumothorax, piglet, 228

intensity of, relation to biochemical outcome, neonatal rats, 49

necrotizing enterocolitis in, piglet, plateletactivating factor protective effects, 1

and reventilation effects, dopamine release and cortical oxygen pressure, newborn piglet, 79

proton magnetic resonance spectroscopy in determining brain damage after, infants, 125

severe birth, iron induced lipid peroxidation and reperfusion injury after, 58

severe perinatal, serum uric acid as index for, neonate, 259

Asthma

allergic, comparison study of assessment tests, children, 299

bronchial

eosinophil cationic protein and myeloperoxidase levels in, children, 322

in primary immune deficiencies, children, 328

childhood

bronchial obstruction measurement, by respiratory inductance plethysmography, 262

exercise-induced, formoterol and salbutamol effects in preventing, 292

exercise-induced, inhaled salmeterol overnight protection, 271

holding chamber for treatment, pressurized metered dose inhalers, 264

jet nebulizer maintenance, bacterial contamination, and performance analysis, 266

methacholine dose-response curves before and during salmeterol treatment, 302

psychosocial factors, 277

psychotherapeutic approach, in emotional disorders, 251

early and late reactions, loratadin and cetiricin effects, guinea pig, 273, simple cost effective peak flow meter, 67

eosinophil cationic protein, seasonal in- crease in serum levels, association with bronchial hyperreactivity, children, 311

intensive care management, children, 359

lung function changes during bronchial provocation testing, children, 117

prevalence of, at four years of age, 314

relationships with disturbed sleep and daytime cognition and behavior, children, 304

with segmenta/lobar collapse, diagnosing differentiation with pulmonary tuberculosis, children, 274

vocal cord dysfunction and, rhinolaryngos-

Atopy copy in differentiating, children, 120

humoral immune responses to immunizing agents, children, 309

manifestations, primary immune deficiencies, children, 328

sensitization

lung function test results, Estonian school age children, 327

prevalence, Estonian school age children, 316

prevalence of, Estonian adolescents, 323

Autoimmune disorders, prevalence of different types, children, 313

Bacterial colonization, evaluation, in gastric aspirates, critically ill neonate, 226

Bacterial infection, congenital, epidemiology and microbiology, VLBW infants with respiratory failure, 336

Bacterial lysate, effects on local and systemic immunity, bronchiectasis children

Bacterial meningitis, interleukin-6 levels in cerebrospinal fluid, 339

Baroreceptor reflex, modulation of heart rate, neonate, 212

Behavior

chronic atopic eczema influence on, children, 64

disturbances, role of anti-epileptic therapy, children, 380

outcome, predictors of, after surgery for congenital heart disease, children, 232

states, development, preterm infants, 138

Bilirubin plasma levels, Sn-protoporphyrin effects on, rats, 14, production, and ceruloplasmin levels, relationship, newborn infant with jaundice, 53

Biochemical outcome, intensity of hypoxia effects on, neonatal rats, 49

Bioelectrical impedance analysis, assessing total body water and weight, neonate, 16

Bisferiens pressure peaks, in radial wave artery, as indicator of patent ductus arteriosus, neonate, 72

Blood

lactate, arterial, significance, critically ill neonates, 57

peripheral, T lymphocyte detection in, preterm infants, 377

transfusion, effects on apnea, bradycardia, tachycardia and oxygen saturation, anemic preterm infants, 367

Blood flow

cerebral

abnormalities of, preterm infants with intracerebral hemorrhage, 25

effects of high frequency oscillation, neonate, 178

near-infrared spectrophotometry in investigating, neonate, 34

sex differences in, premature infants, 13

skin, thermoregulatory fluctuations, and heart rate variability in infants, association with SIDS, 350

velocity

physiological variables effects on, during mechanical ventilation, preterm infants, 182

superior mesenteric artery and renal artery, measurements of, interobserver reliability, neonates, 253

Blood pressure

arterial, dexamethasone effects on, preterm infants with bronchopulmonary dysplasia, 27

changes, pulse arrival time evaluation as marker for, after cardiac surgery, infants and children, 371

mean arterial, and cerebral blood volume cyclic fluctuations, preterm infants, 209

oscillometric, accuracy of measurement, critically ill neonates, 73

surfactant replacement therapy effects on, newborn piglets, 162

Blood volume

cerebral

cyclic fluctuations in, and mean arterial blood pressure, preterm infants, 209

near-infrared spectrophotometry in investigating, neonate, 34

suboptimal, after cardiac surgery, infants, 370

Body

composition

analysis of, VLBW infants, 122

assessment of, dual X-ray absorptiometry, term and preterm infants, 188

changes in, during weight reduction, obese children, deuterium dilution measurement, 70

4-compartment model, deuterium dilution with dual-energy $\mathrm{x}$-ray absorption, 68

role of TOBEC in assessing, infants, 33

fat, estimations, by total body electrical conductivity and 18-oxygen dilution methods, infant, 32

water, total, bioelectrical impedance analy-

Bone sis of, neonate, 16

marrow transplant, in children, ethical and medico-legal concerns, 384

mineral

content, analysis of, VLBW infants, 122

content, evaluation of, after gonadotropin-releasing hormone treatment, children, 240

density, after kidney transplantation, children, 63

Bowel

disease, inflammatory, growth failure and malnutrition in children with, 30

resection, absorptive capacity after, neonates, 126

Bradycardia

blood transfusion effects on, preterm infants, 367

body position influence on, preterm infants, 118

Brain. see also entries under Cerebral

abnormalities, ${ }^{1} \mathrm{H}$ magnetic resonance spectroscopy, after perinatal asphyxia, infants, 186

activity, inhaled nitric oxide effects on, lamb, 133

blood flow. see Blood flow

damage

after asphyxia, role of proton magnetic resonance spectroscopy and cerebral 
hyperperfusion in determining, infants, 125

ischemic, producing in newborn piglet, cerebral vessel anatomy, and comparison with human, 88

'H-MRS, measurement of water compartments and detection within myelin layers, 69

ischemic-hemorrhagic lesions, correlation between cerebral visual impairment, neurodevelopmental outcome, neonates, 60

ischemic-hemorrhagic lesions, incidence of, preterm infants, 51

lactate, and $\mathrm{N}$-acetylaspartate/choline ratios, after hypoxia-ischemia, newborn piglet, 134

nitric oxide synthetase, activity, after hypoxia, newborn piglet, 82

oxygen saturation, fetal, measurement during labor, predicting acid-base state at delivery, 6

parietal cortex, influence of hypoxia and ischemia, neonatal rats, 48

Breath-holding spells, vagal reflex association with, children, 89

Breathing patterns

changes, adaptive response to nasogastric tube, VLBW infants, 204

neonate, after prenatal exposure to cocaine, 203

Breath test, ${ }^{13} \mathrm{C}$-phenylalanine, and liver function testing for measuring function, children, 31

British Paediatric Surveillance Unit, investigating rare childhood disorders, beneficial health effects resulting, 179

Bronchial hyperreactivity

association, seasonal increase eosinophil cationic protein serum levels, 311

eosinophil cationic protein levels correlation with, methacholine bronchial provocation test, children, 310

Bronchial obstruction, measurement of, by respiratory inductance plethysmography, asthmatic children, 262

Bronchial reactivity, comparison study of assessment tests, children, 299

Bronchiectasis, local and systemic immunity, bacterial lysate effects on, children, 294

Bronchiolitis

acute, clinical and functional response to salbutamol, 275

oxygen therapy and maturational differences, infants, 260

respiratory mechanics, infants, 291

respiratory syncytial virus, decay of maternally derived antibodies against, neonates and infants, 333

Bronchitis

comparison study of assessment tests, children, 299

wheezing, in primary immune deficiencies, children, 328

Bronchoalveolar lavage

fluid, interleukin-8 levels in, infants with RDS, 185

role

determining macrophage infiltration, preterm infants with RDS, 171

diagnosis and prognosis, chronic lung damage, ventilated neonates, 295

Bronchodilator therapy, effectiveness of, bronchiolitis, 275

Bronchogenic cyst, diagnosing, differentiation with pulmonary tuberculosis, children, 274
Bronchopneumonia, diagnosing, differentiation with pulmonary tuberculosis, children, 274

Bronchopulmonary aspergillosis, allergic, diagnosis in cystic fibrosis patients, 318

Bronchopulmonary dysplasia

amino acid levels after dexamethasone treatment, preterm infants, 29

bronchoalveolar lavage determination of macrophage infiltration, preterm infants, 171

dexamethasone effects on diuresis, serum urea and blood pressure, preterm infant, 27

dexamethasone effects on spontaneous motor behavior, preterm infants, 28

effects of inhaled nitric oxide, preterm infants, 169

prolonged ventilation, poor prognosis after, infants, 303

Bronchopulmonary effects, inhaled nitric oxide, refractory hypoxemia, neonate, 197

Bronchoscopy, flexible, and upper airway obstruction, lung function testing in, preterm and term infants, 5

Buccal mucosal cell, evaluating vitamin $\mathrm{E}$ nutritional status, infants and children, 103

Budesonide and nebulized adrenaline treatment for coup, comparison study, 301

Bypass bridge, opening during ECMO, contribution to cerebral hemorrhage, piglet, 128

Calcium metabolism, after gonadotropin-releasing hormone therapy, precocious puberty, children, 240

Calorimetry, indirect

assessing energy expenditure, VLBW infants, 96

energy metabolism consumption determination after chronic valproate treatment, children, 159

Cancer, childhood

megestrol effects on anorexia and weight loss in, 12

recombinant human erythropoietin treatment for, chemotherapy-induced anemia, 18

Candida, and Torulopsis species, monocytestimulating capacity, infants, 97

Carbamate poisoning, oxime therapy effects, infants, 366

Carbohydrate-deficiency glycoprotein syndrome, characterization of, 150

Carboxyhemoglobin, and ceruloplasmin concentration relationship, newborn infant with jaundice, 53

Cardiac output, Fick principle versus thermodilution method for measuring, comparison study, 372

Cardiorespiratory profile, small-for-gestational age infants, born after intrauterine growth retardation, 272

Carnitine deficiency, evaluation, malnourished children, 227

$\alpha$-Caseins, IgE-ELISA specific for, evaluation of, 217

Catheterization, cardiac, cerebral blood volume measurement before, near infrared absorption spectroscopy, children and adolescents, 255

Ceftazidime, pharmacokinetics, preterm infants, 329

Central nervous system, depression, carbamate poisoning, oxime therapy effects, infants, 366
Cerebral see also entries under Brain

Cerebral perfusion, cyclic fluctuations in intracranial hemorrhage, preterm infants, 209

Cerebral venous saturation, measurement of near infrared absorption spectroscopy, children and adolescents, 255

Cerebral vessels, anatomy of, newborn pig, comparison with human, 88

Cerebrospinal fluid

concentration, children with tuberculosis meningitis, 334

interleukin-6 levels in, patients with bacterial meningitis, 339

Cetiricin, effects, early and late asthmatic reaction, guinea pig, 273

Children

acute lymphoblastic leukemia

diagnosis of secondary leukemia, 20

serum transferrin receptor and erythropoietin role as indicators of erythropoiesis, 110

anemia of infection, prevalence of, 77

asthma

formoterol and salbutamol effects, preventing exercise-induced asthma, 292

holding chamber for treatment, pressurized metered dose inhalers, 264

intensive care unit management, 359

jet nebulizer maintenance, bacterial contamination, and performance analysis, 266

psychotherapeutic approach to treatment, emotional disorders, 251

relationships with cognition, behavior and sleep disturbances, 304

bone marrow transplant, ethical and medico-legal concerns, 384

bronchiectasis, local and systemic immunity, bacterial lysate effects

cancer

megestrol effects on anorexia and weight loss in, 12

recombinant human erythropoietin treatment for, chemotherapy-induced anemia, 18

chronic disease, quality of care analysis, parent and physician views, 144

chronic gastritis, semiconductor laser treatment for, 194

conceptualization of disease and treatment, 123

cystic fibrosis, positive expiratory pressure role in avoiding, gastro-esophageal reflux symptoms during chest physiotherapy, 267

elementary school age, acute respiratory problems, life-style and activity patterns comparison study, 8

epidemiology of adult respiratory distress syndrome, 363

Haemophilus influenzae infections, changing epidemiology of after initiation of immunization program, 76

IDDM

Coxsackie virus infection prevalence in see Diabetes mellitus, insulin dependent

onset mortality rates, 239

pancreas size, ultrasound evaluation, 241

poor metabolic control as risk factor for color vision impairment, 132

impetigo, occurrence and treatment of, 397

inflammatory bowel disease, growth failure and malnutrition, 30 
malnourished, plasma free carnitine and albumin levels in, 227

pre-school age

cystic fibrosis, head growth measurement, 75

health knowledge, attitudes and behaviors in families, 195

prevalence of allergic sensitization to common allergens, at four years of age, 314

pulmonary tubereulosis

evaluation and diagnosis, 274

role of lateral chest radiograph in diagnosing, 330

retinoblastoma, molecular analysis of $\mathrm{Rb}$ 1 segregation in families, early diagnosis, 116

Schonlein Henoch syndrome, von Willebrand factor and factor XIII determination in, 376

school age

asthmatic, measurement of bronchial obstruction, respiratory inductance plethysmography, 262

juvenile chronic arthritis, psychosocial functioning, 383

lung function test results in Estonia, 327 multiple trauma, case review, 368

prevalence of atopic sensitization and respiratory symptoms, Estonian children, 316

recurrent abdominal pain, prevalence and relation to psychological cause, 306

respiratory problems prevalence, 298

tuberculosis, evaluation of symptoms, clinical features and chest radiography features, 344

urinary cotinine excretion, after passive exposure to cigarette smoke, 216

short stature, lung function testing, 305

transient synovitis of the hip, prevalence and management, 242

Cholestasis, neonatal, bile acid concentrations in, preterm infants, 202

Chorionic villus sampling, prenatal diagnosis of hemophilia, 44

Chromatic sense, impairment, poor metabolic control as risk factor for, IDDM children, 132

Chromatography

high performance liquid, analysis of surfactant phospholipid composition and saturation, 263

high pressure liquid, evaluating $\alpha$-tocopherol blood cells, for determination of nutritional status of vitamin $\mathrm{E}$, infants and children, 103

Chromosome, $X$, methylation pattern, females with low factor VIII:C level, 2

Chronic disease, pediatric, quality of care analysis, parent and physician views, 144

Cigarette smoke

passive exposure to, urinary cotinine excretion relationship, children, 216

prenatal exposure to, importance as risk factor for SIDS, 356

Cocaine. see also Substance abuse

prenatal exposure to, breathing patterns of infants, 203

Cognition, relationships with asthma and behavior, children, 304

Cognitive development

prenatal exposure to coumarins, at 8-10 years of age, 237

VLBW infants at 8 years of age, 174

Cognitive processing, deficits, effects of pos- terior corpus callosum damage, preterm infants at 8 years of age, 107

Collagen, type III, disturbed metabolism as cause of juvenile hyaline fibromatosis, 393

Colony-stimulating factor, recombinant human granulocyte, treatment for neonatal neutropenia, 19

Complement activation

PAF in causing, preterm infants with IRDS, 36

role, indicator of early onset infection, preterm infants, 257

Conjoined twins, medical ethics related to separation, 170

Conversion disorders, parent's free descriptions, diagnosing, 385

Copper, and molybdenum metabolism interrelationship, preterm infants, 210

Cortical oxygen pressure, and dopamine release, asphyxia and reventilation effects on, newborn piglet, 79

Coumarins, prenatal exposure to, neurological and cognitive outcome, at 8-10 years of age, 237

Coxsackie virus, infection, chronic form, children with IDDM. see Diabetes mellitus, insulin dependent

Craniofacial anomalies, obstructive sleep apnea in children with, 94

Croup

nebulized adrenaline plus dexamethasone versus budesonide treatment, comparison study, 301

treatment in pediatric emergency department, 270

Curantil, effects, treatment for respiratory disease, children, 296

CYP21 gene, deletion of, recombination event causing, steroid 21-hydroxylase deficiency, 56

Cystathionine- $\beta$-synthase gene, mutation, association with homocystinuria, 111

Cystic fibrosis

allergic bronchopulmonary aspergillosis, diagnosis, 318

chest radiograph scoring system, reliability of

head growth measurement, children from birth to four years of age, 75

intravenous antibiotics effects on lung functions and inflammatory markers in bronchial secretions, 55

modification of nasal membrane potential difference, inhaled sodium channel inhibitors, mice, 74

neutrophil elastase inhibition in sputum, leukoprotease inhibitor, 297

positive expiratory pressure therapy, avoiding gastro-esophageal reflux symptoms during chest physiotherapy, children and adolescents, 267

postural drainage effects on gastro-esophageal reflux, infants, 41

salivary IgA antibody titers to bacterial antigens, with and without malnutrition, 308

Cystic leucomalacia, demonstrating cerebral metabolic abnormalities, ${ }^{1} \mathrm{H}-\mathrm{MR}$ spectroscopy, infants, 81

Cystourethrography, fluoroscopic voiding, reliability of, detecting vesicoureteral reflux, infants and children with urinary tract infection, 211

Cytokines

production, by MNC from synovial fluid, juvenile rheumatoid arthritis, 321

serum levels, and superoxide anion gener- ation, in mothers and newborns during peripartum, 38

Cytomorphology, diagnosing secondary leukemia, children with acute lymphoblastic leukemia, 20

Cytotoxic T cell, and IgA responses, measles, vaccinated high school children, 332

Dermatitis, primary immune deficiencies, children, 328

Deuterium dilution, measuring body composition changes during weight reduction, obese children, 70

Development

assessment, Ankara Developmental Screening Inventory, and its environmental correlates, 381

behavioral states, preterm infants, 138

cognitive, VLBW infants at 8 years of age, 174

delays, VLBW infants at 8 years of age, 173

motor skill, early treated phenylketonuria, children, 191

outcome

chronic atopic eczema influence on children, 64

effects of aluminum contamination of feeding solutions, preterm infants, 24

family structure and stability impact on, preterm infant, 85

persistent pulmonary hypertension, risks of transport for ECMO versus conventional treatment, infant, 86

predictors of, after surgery for congenital heart disease, children, 232

predictors of, ELBW infants at 5 years of age, 243

preterm infant, telephone interview, 214

preterm infants, at 5 years of age, 112

qualitative assessment of early walking, preterm and full-term infants, 84

thyroxine administration, very preterm infants, 250

Dexamethasone

amino acid levels after, preterm infants with bronchopulmonary dysplasia, 29

association with low triiodothyronine concentrations, arterial hypotension, ELBW infants, 66

effects

diuresis, serum urea and blood pressure, preterm infants with bronchopulmonary dysplasia, 27

spontaneous motor behavior, preterm infants with bronchopulmonary dysplasia, 28

on $\mathrm{T}$ cell proliferating capacity, neonate 105

and nebulized adrenaline treatment for croup, comparison study, 301

Diabetes, transient neonatal, early manifestation of inherited insulin resistance, intrauterine growth retardation effects on, 208

Diabetes mellitus, insulin dependent

chromatic sense and metabolic control relationship, children, 132

Coxsackie virus infection in children with, 113

onset mortality rates, children and adolescents, 239

ultrasound evaluation of pancreas size, children and adolescents, 241

Diarrhea, acute, early refeeding after onset, infants, 176

Dicarboxylic acid, urinary excretion rate, Zellweger syndrome patients, 152 
Dietary therapy, plasma phenyllactate evaluation, in phenylketonuria, 95

Diet, effect on body composition and bone mineral content, VLBW infants, 122

1,25 Dihydroxyvitamin D3 receptors, measurement of, cord peripheral mononuclear cells, term infants, 167

Dioxin

effects on thyroid hormone levels, pregnant women and their infants, 115

levels, effects on fetal neurodevelopment and relation to living area, 114

Diphtheria, humoral immune responses, atopic and nonatopic children, 309

Disease surveillance, British Paediatric Surveillance Unit, investigating rare childhood disorders, beneficial health effects resulting, 179

Diuresis, dexamethasone effects on, preterm infants with bronchopulmonary dysplasia, 27

Dobutamine, and dopamine treatment RDS, effects on cardiac function and hypotension, infants, 247

Dopamine

and dobutamine treatment, RDS, effects on cardiac function and hypotension, infants, 247

effects on heart function and blood pressure, hypotensive, preterm infants, 136

release, and cortical oxygen pressure, asphyxia and reventilation effects, newborn piglet, 79

Doppler

laser, evaluation of heart rate and skin blood flow fluctuations, infants, 350

transcranial, guidelines for safe use, neonate, 101

Down syndrome, first disclosure to parents, audio-recordings of discussion, helping understanding of parents, 389

Dual-energy X-ray absorption, and deuterium dilution, 4-compartment model of body composition, 68

Dust mite allergy, HLA-class II molecule relevance in immune response, children, 325

Echocardiography, analysis of transient interarterial left to right shunts, neonate, 147

ECMO. see Oxygenation, extracorporeal membrane

Ecological zone, variations in, effects on lipid peroxidation activity in erythrocytes, neonate, 207

Eczema

atopic, prevalence of, at four years of age, 314

chronic atopic, influence on child behavior and mothers attitude, 64

Education

attainment, VLBW infants at 8 years of age, 174

improving fine and gross motor skills, VLBW infants, 173

pediatrician, relating diagnoses to children, 123

EEG, suppression, after augmented breaths during apnea, preterm infants, 358

ELBW. see Infant, extremely low birth weight

Electromagnetic interference, during near infrared spectroscopy, role of ferrite beads in eliminating during neonatal data collection, 140

Electron spin resonance, study, erythrocyte cell membranes, in HallervordenSpatz disease with ananthocytosis, children, 40

ELISA. see Enzyme-linked immunosorbant assay

Emergency department, pediatric, treatment of croup, 0

Emotional disorders, asthmatic children with, psychotherapy in treatment, 251

Emotional outcome, predictors of, after surgery for congenital heart disease, children, 232

Encephalopathy, hypoxic ischemic, intracranial lesions in, ultrasound and autopsy correlation, infants, 244

Endocytosis, surfactant lipid, surfactant protein A role in, 219

Endoplasmic reticulum, carbohydrate-deficiency glycoprotein syndrome relation to, 150

Endorphins, decrease plasma beta, after treatment for gastro-esophageal reflux, in hospitalized infants for acute life threatening episodes, 352

Endothelin, 1-21 plasma levels, preterm infants, 143

Endothelin-1, excretion, urinary, after furosemide treatment, neonate, 223

Endotoxin, erythrocyte protection, umbilical cord blood analysis, 193

Energy expenditure

calculation of, $\mathrm{CO}_{2}$ production role in, and nutritional intake, 15

indirect calorimetry versus ${ }^{2} \mathrm{H}^{18} \mathrm{O}$ determination, VLBW infants, 96

Energy metabolism composition, after chronic valproate treatment, children, 159

Enterocolitis, necrotizing

absorptive capacity of bowel after resection for, neonate, 126

asphyxiated newborn piglet, platelet-activating factor protective effects on, 1

role of elevated endothelin 1-21 levels in causing, preterm infants, 143

Enzyme-linked immunosorbant assay

IgE evaluation, specific for $\alpha$-caseins, 217

role, identifying allergic bronchopulmonary aspergillosis in cystic fibrosis patients, 318

Eosinophil cationic protein

seasonal increase in serum levels, association with bronchial hyperreactivity, children, 311

serum levels, bronchial hyperreactivity correlation, methacholine bronchial provocation test measurement, children, 310

Epidemic, tinea capitis, in Rotterdam, 392

Epidemiology

adult respiratory distress syndrome in children, 363

circumscribed scleroderma, children, 390

congenital bacterial infections, VLBW infants with respiratory failure, 336

Haemophilus influenzae infection, changes in after initiation of immunization program, children, 76

multi-drug resistant Salmonella typhi, Pakistani children, 342

resistant Streptococcus pneumoniae, children, 340

Epilepsy

sleep disturbance effects on psychological function, children, 387

treatments, causing behavior disturbances, children, 380
Epithelial cells, Streptococcus pneumoniae adhesion to, 338

Erythematosus

subacute cutaneous lupus, SS-A antibodies in children, 373

systemic lupus, SS-A antibodies in children, 373

Erythrocytes

electron spin resonance study of, Hallervorden-Spatz disease with ananthocytosis, children, 40

iron release in, evaluating risk of oxygen radical toxicity, neonates, 39

mechanical fragility, infants, 198

umbilical cord blood analysis, endotoxin protection, neonate, 193

volume

flow cytometry in determining, anemic fetus and infants, 249

suboptimal, after cardiac surgery, infants, 370

Erythropoiesis

serum transferrin levels, as indicator of, adolescent males, 11

serum transferrin receptor and erythropoietin as indicators of, children with acute lymphoblastic leukemia, 110

Erythropoietin

recombinant human

treatment, anemia of prematurity, nutrition effects on effectiveness, preterm infants, 17

treatment, chemotherapy-induced anemia, 18

role, indicator of erythropoiesis, children with acute lymphoblastic leukemia, 110

Exercise, metabolic response to, lambs with aortopulmonary shunt, 16

Extracorporeal membrane oxygenation. see Oxygenation, extracorporeal membrane

Factor VIII:C, level, methylation pattern analysis, in females, 2

Factor XIII, determination of, in Schonlein

Family Henoch syndrome, children, 376

pre-school age children, health knowledge, attitudes and behaviors, 195

structure and stability, impact on developmental outcome, preterm infants, 85

telephone interview, outcome of preterm infant, 214

Fat

absorption, structural position and palmitic acid levels in infant formulas effects on, 47

body, estimating, by total body electrical conductivity and 18-oxygen dilution methods, infant, 32

composition, adipose tissue, ${ }^{13} \mathrm{C}$ MRS in measuring, infants, 91

content, assessment of, dual X-ray absorptiometry, preterm infants, 188

Fat-free mass, estimations of, by total body electrical conductivity and 18-oxygen dilution methods, comparison study, infants, 32

Fatty acids

adipose tissue, ${ }^{13} \mathrm{C}$ MRS in measuring, infants, 91

essential, medium chain triglyceride content in infant formula effects on, 46

long chain polyunsaturated, supplementation, in infant formulas, effects on endogenous synthesis, 45 
Feeding

early resumption of, after acute diarrhea, infants, 176

solutions, aluminum contamination of, effects on long-term developmental outcome, preterm infants, 24

Fetus

anemia, erythrocyte volume, flow cytometry role in determining, 249

cerebral oxygen saturation measurement, during labor, predicting acid-base state at delivery, 6

dioxin and polychlorinated biphenyl effects on thyroid hormone levels, 115

hemodynamics, cortical impedance and neuronal loss relationship after ischemia, sheep, 149

hypoxia, differentiation between acute and prolonged, twins, 142

liver and intestine development, xanthine oxidase activity and immunoreactive enzyme protein relation in, 129

liver and thymus immunophenotype evaluation, 222

neurodevelopmental effects of dioxin and polychlorinated biphenyl levels in mother, relation to living area, 114

overgrowth during diabetic pregnancy, factors for, 166

in utero substance exposure, follow-up of children after 14 years, 61

Fever, role of antipyretics in reducing, children, 62

Fiberobronchoscopy, stridor, infants, 288

Fibromatosis, juvenile hyaline, defective metabolism of collagen fibrils role in causing, 393

Fick principle, continuous measurement of cardiac output, comparison with thermodilution method, children, 372

Flow cytometry, determining erythrocyte volumes, anemic fetus and infants, 249

Food intolerance, prevalence of, at four years of age, 314

Foramen ovale, transient, incompetence, neonates, 147

Formoterol, preventing exercise-induced asthma, children, 292

Formula, infant

long chain polyunsaturated fatty acid supplementation, effects on endogenous synthesis, 45

medium chain triglyceride content, effects on essential fatty acids, 46

partially hydrolyzed whey, nutrient balance, preterm infants, 52

structural position and palmitic acid levels effects on fat absorption and mineral balance, 47

Functional residual capacity

measurement of, helium/oxygen washout gas, preterm infants, 278

PEEP in maintaining, mechanically ventilated preterm infants, 229

Furosemide, administration, urinary endothelin-1 excretion after, neonate, 223

Galactosemia, magnetic resonance spectroscopy, pathogenesis of neurological abnormalities, 163

Gastritis, chronic, treatment with semiconductor laser, children, 194

Gastroenteritis, acute, as cause of anemia, infants and children, 77

Gastro-esophageal reflux

during chest physiotherapy, cystic fibrosis children and adolescents, postural drainage versus positive expiratory pressure therapy, 267

decreased plasma beta endorphins after treatment for, hospitalized infants for acute life threatening episodes, 352

postural drainage effects on, infant with cystic fibrosis, 41

Gene mutation, cystathionine- $\beta$-synthase, association with homocystinuria, 111

Gene therapy, congenital hyperbilirubinemia, 254

Genetic analysis, umbilical cord blood, monozygotic and dizygotic twins, 315

Genetic segregation, $\mathrm{Rb}-1$, in families of children with retinoblastoma, early diagnosis, 116

Gestational age, effects, plasma protein activation, respiratory distress syndrome, preterm ventilated rabbits, 35

Glomerular disease, $\mathrm{C}_{5 b-9}$ deposition, children, 17.5

Glucocorticoids

administration, antenatal, VLBW and preterm infants, outcome at 5 years of age, 236

sensitivity, of neonatal leukocytes, 105

Gluconeogenesis, liver, tumor necrosis factor- $\alpha$ regulation, rats, 256

Glucose

concentration, immunoradiometric assay role in determining, neonate, 93

microdialysis determination of levels, small-for-gestational age infants, 98

postasphyxial administration, effects, hyperinsulinism with bilateral pneumothorax, piglet, 228

production, glycerol, preterm infant during first postnatal day, 225

Glucose-6-phosphate dehydrogenase, deficiency, neonatal screening for, sex distribution and role of paternity, 104

Glutamate, antagonist, effects on NMDA receptor, reducing cerebral injury after stroke, 83

Glycerol, glucose production, preterm infant during first postnatal day, 225

Gonadotropin-releasing hormone, therapy, precocious puberty, calcium metabolism after, 240

G-protein, stimulatory

activity in pseudohypoparathyroidism, 145

activity in vitamin $\mathrm{D}$ deficiency rickets, infants, 146

Granulocyte-macrophage colony-stimulating factor, stimulating capacity of Candida and Torulopsis species, infants, 97

Growth

failure and malnutrition, children with inflammatory bowel disease, 30

retardation, intrauterine

cardiorespiratory profile, infants, 272

effects, on mortality and developmental outcome at 5 years of age, preterm infants, 112

inherited insulin resistance as early manifestation as transient neonatal diabetes, 208

intelligence and academic achievement after, short-stature children, 121

nutritional needs, small- versus appropriate-for-gestational age VLBW infants, 187

recombinant human growth hormone treatment effects on protein metabolism, preterm infants, 231

Growth hormone deficiency, lung function testing, children, 305

recombinant human, effects on protein metabolism, intrauterine growth retardation, preterm infants, 231

Haemophilus influenzae, changing epidemiology of, voluntary immunization program, 76

Hair, maternal, analysis of, detecting heavy metal exposure during pregnancy, 189

Hallervorden-Spatz disease, with acanthocytosis, electron spin resonance study of erythrocyte cell membranes, children, 40

Head growth, measurement of, cystic fibrosis children, birth to four years of age, 75

Health care

assessing performance of pediatric intensive care unit, 362

quality of, children with chronic diseases, parent and physician views, 144

Health promotion, practices of families with Heart pre-school aged children, 195

function

$\alpha$ - and $\beta$-adrenoceptor relationship effects on, 26

dopamine effects, hypotensive, preterm infants, 136

infants with RDS, 247

obstructive sleep apnea effects on, children, 94

performance, during high frequency oscillation, neonate, 178

Heart disease

complex congenital, continuous intravascular $\mathrm{SvO}_{2}$ monitoring, term and preterm infants, 365

congenital, behavioral and emotional outcome predictors after surgery, children, 232

Heart rate

control, dysfunction, association with thermoregulation, infants, 350

modulation, baroreceptor reflex, neonate, 212

and QT interval, during 1st year of life, SIDS association, 354

variability, association with SIDS, 353

Heart surgery

blood volume and erythrocyte volume after, 370

development of severe pulmonary hypertension after, inhaled nitric oxide effects on, infants, 360

pulse arrival time evaluation, marker of blood pressure changes after, infants and children, 371

Helium/oxygen washout gas, measuring functional residual capacity, preterm infants, 278

Hemodynamics

cardiopulmonary, changes in after indomethacin treatment, preterm infant,

cortical impedance, and neuronal loss relationship after ischemia, fetal sheep 149

effects of $\mathrm{CO}_{2}$ changes during ECMO, piglet, 127

inhaled nitric oxide effects on, lamb, 133

phototherapy effects on, preterm infants, 22

Hemoglobin

fetal, spectrophotometry role in measuring, term and preterm neonates, 364

role, predictor of plasma lactate levels, 87 
Hemophilia, prenatal diagnosis, chorionic villus sampling and polymerase chain reaction methods, 44

Hemophilia A, methylation pattern analysis, females, with low factor VIII:C level, 2

Hemorrhage

cerebral, opening of bypass bridge during ECMO role in causing, piglet, 128

intracerebral, cerebral blood flow disturbances, preterm infants, 25

intracranial, cyclic fluctuations in cerebral perfusion and blood pressure in, preterm infants, 209

intraventricular, elevated endothelin 1-21 levels in causing, preterm infants, 143

ischemic, incidence of, preterm infants, 51

Hemosiderosis, idiopathic pulmonary, antineutrophil cytoplasmic antibodies in, children, 307

Hep-2 antibody, prevalence, incidence and relevance, respiratory syncytial virus infection, infants hospitalized, 335

Hepatitis, acute viral, as cause of anemia, infants and children, 77

Hering-Breuer deflationary reflex, standardization of, and factors initiating, infants, 90

Hernia, congenital diaphragmatic

biochemical lung immaturity in, neonate, 234

lung volume and mechanics, neonates and infants, 180

role of prenatal hormonal therapy in improving pulmonary morphology, rats, 135

surfactant deficiency role in, lung fibroblast immaturity, 258

Hib. see Haemophilus influenzae type b

Hip, transient synovitis, prevalence and management, children, 242

Histiocytosis, Langerhans cell, skin lesions in, children, 391

Histography, $\mathrm{pO}_{2}$, analysis of forearm oxygenation, 139

HIV. see Human immunodeficiency virus

Homocystinuria, cystathionine- $\beta$-synthase gene mutations association with vitamin $B 6$ response, 111

Hormonal therapy, prenatal, pulmonary development after, congenital diaphragmatic hernia, 135

Hospitalization, children, acute respiratory problems, life-style and activity patterns comparison study, 8

HPLC. see Chromatography, high performance liquid

Human immunodeficiency virus. see also Acquired immunodeficiency syndrome

lymphocyte lifespan relevance to, children versus adult, 351

mother-to-child transmission, parity influence on, 106

Hyaline fibromatosis, juvenile, disturbed metabolism of type III collagen as cause, 393

Hyaluronan concentration

lung, surfactant and $\mathrm{N}$-acetylcysteine in stimulating, 102

in lung, infants which died in 1 st day after birth, 205

21-Hydroxylase deficiency, classical, frequency of, in Malaysia, 119

Hyperactivity, anti-epileptic therapy causing behavior disturbances, children, 380

Hyperbilirubinemia

congenital, gene therapy, 254 neonatal, screening for glucose-6-phosphate dehydrogenase deficiency, paternity and sex distribution, 104

phototherapy treatment for, hemodynamic consequences after, preterm infants, 22

Sn-protoporphyrin effects on, rats, 14

Hyperlactatemia, arterial blood lactate levels role, determining prognosis, critically ill neonates, 57

Hyperoxia, lung injury, surfactant effects on monocytes and neutrophils during, 108

Hyperperfusion, cerebral, determining brain damage after asphyxia, infants, 125

Hyperphenylalaninemia, persistent, intelligence outcome and cranial MRI findings, 252

Hypertension

persistent pulmonary, risks of transport for ECMO versus conventional treatment, and developmental outcome, infants, 86

pulmonary

development after cardiac surgery, inhaled nitric oxide effects on, infants, 360

nitric oxide, improving oxygenation, neonate, 4

Hypoglycemia, microdialysis determination of, small-for-gestational age infants, 98

Hypoplasia, pulmonary

diagnosing, differentiation with pulmonary tuberculosis, children, 274

nitrofen exposure in early lung development, rats, 265

Hypotension

arterial, dexamethasone treatment association with low triiodothyronine concentrations, ELBW infants, 66

dopamine effects on heart function and blood pressure, preterm infants, 136

increased plasma cGMP, preterm infants, 137

infants with RDS, 247

Hypothyroxinemia, transient, clinical outcome after thyroxine administration, very preterm infant, 250

Hypoxemia

body position influence on, preterm infants, 118

plasma lactate as indicator of, in identifying anemia, piglet, 87

refractory, bronchopulmonary effects of inhaled nitric oxide, neonate, 197

Hypoxia

cerebral nitric oxide synthetase activity after, newborn piglet, 82

fetal, differentiation between acute and prolonged, twins, 142

inhaled nitric oxide effects, preterm infants with bronchopulmonary dysplasia, 169

intensity of, relation to biochemical outcome, neonatal rats, 49

neonatal, influence of, in parietal cortex, rats, 48

Hypoxia-ischemia

cerebral lactate and $\mathrm{N}$-acetylaspartate/choline ratios after, newborn piglet, 134

proton magnetic resonance spectroscopy, high spin-spin relaxation times, newborn piglets, 42

reoxygenation, purine levels in, 224

transient, increased apoptosis in brain after, newborn piglet, 158
Ibuprofen and paracetamol, treatment for febrile seizures, children, 62

ICF syndrome. see Immunodeficiency, Centromeric instability, and Facial dysmorphisms (ICF) syndrome

IDDM. see Diabetes mellitus, insulin dependent

IgE, ELISA evaluation, specific for $\alpha$-caseins, 217

Imaging. see also specific types

magnetic resonance, correlation with cerebral visual impairment and neurodevelopmental outcome, hemorrhagic-ischemic brain lesions, neonate, 60

Immune deficiency

immaturity of $\mathrm{T}$ lymphocyte functional receptors in, preterm infant, 377

primary

atopic manifestations of, children, 328

and autoimmunity, prevalence of different types, children, 313

Immune response, tetanus and diphtheria antigens, atopic and nonatopic children, 309

Immune system, qualitative and quantitative differences in, allergic children, 317

Immunity, local and systemic, bronchiectasis, bacterial lysate effects on, children, 294

Immunization. see also Vaccination

measles, strategies for, monkey, 331

program, changing epidemiology of $\mathrm{Hae}$ mophilus influenzae infection, children, 76

tetanus and diphtheria humoral immune responses, atopic and nonatopic children, 309

Immunodeficiency, Centromeric instability, and Facial dysmorphisms (ICF) syndrome, case study, 378

Immunofluorescence, direct, role in diagnosing viral respiratory infections, 343

Immunoglobulin, administration, correlation with fibronectin concentrations during infection, LBW infant, 379

Immunohistochemical analysis, determining macrophage infiltration, preterm infants with RDS, 171

Immunophenotyping, lymphocyte subpopulations, whole blood microassay role in, neonates and infants, 245

Immunoradiometric assay, determining insulin-glucose relationship, neonate, 93

Impetigo, occurrence and treatment by the general practitioner, children, 397

Indomethacin, cardiopulmonary hemodynamic changes after, preterm infants, 21

Infant. see also Neonate

allergy development, relation to nutritional challenge and infectious disease, 235

anemia

erythrocyte volume, flow cytometry in determining, 249

of infection, prevalence of, 77

of prematurity, timing of EPO administration, 215

asphyxia, role of proton magnetic resonance spectroscopy and cerebral hyperperfusion in determining brain damage after, 125

bronchiolitis, oxygen therapy and maturational differences, 260

bronchopulmonary dysplasia, prolonged ventilation as indicator of poor prognosis, 303 


\section{SUBJECT INDEX TO ABSTRACTS}

congenital diaphragmatic hernia, lung volume and mechanics, 180

cutaneous malignant lymphoma, B-cell, case study, 375

cystic fibrosis

head growth measurement, 75

postural drainage effects on gastroesophageal reflux, infants, 41

cystic leucomalacia, cerebral metabolic abnormalities in, 'H-MR spectroscopy, 81

1,25 dihydroxyvitamin D3 receptor measurement, cord peripheral mononuclear cells, 167

extremely low birth weight

prediction of outcome at 5 years of age, 243

triiodothyronine concentrations, association with dexamethasone treatment for hypotension or severe lung disease, 66

two-year outcome, 50

fat-free mass and body fat estimations, by total body electrical conductivity and 18-oxygen dilution methods, 32

ICF syndrome, case study. see Immunodeficiency, Centromeric instability, and Facial dysmorphisms (ICF) syndrome

IDDM, onset mortality rates, 239

low birth weight

fibronectin concentrations during infection, and correlation with immunoglobulin administration, 379

parenteral nutrition, lipid tolerance levels, 43

lung disease, synchronized and conventional intermittent ventilation, comparison study, 23

nutrition, iron-fortified cereal, vitamin $\mathrm{C}$ role in hydroxyl radical formation in,

nutritional assessment, role of TOBEC and anthropometry, 33

patient triggered ventilation, lung function and reflex activity influence on success of, 276

persistent pulmonary hypertension, risks of transport for ECMO versus conventional treatment, and developmental outcome, 86

prenatal exposure to cocaine, breathing pattern changes, 203

preterm

aluminum contamination of intravenous feeding solutions, effects on longterm developmental outcome, 24

amoxicillin pharmacokinetics, 10

anemia of prematurity, recombinant human erythropoietin treatment for, nutrition effects on effectiveness, 17

antenatal glucocorticoid administration, outcome at 5 years of age, 236

behavioral states development, 138

blood transfusion effects on apnea, bradycardia, tachycardia, and oxygen saturation, 367

body position influence on apnea, hypoxemia and bradycardia, 118

bronchopulmonary dysplasia, amino acid levels after dexamethasone treatment, 29

bronchopulmonary dysplasia, dexamethasone effects on diuresis, serum urea, and blood pressure, 27

bronchopulmonary dysplasia, dexamethasone effects on motor behavior, 28 bronchopulmonary dysplasia, effects of inhaled nitric oxide, 169

cardiopulmonary hemodynamic changes after indomethacin treatment, 21

ceftazidime pharmacokinetics, 329

complement activation during first hours of life, indicator of early onset infection, 257

computer-controlled ventilation, using spontaneous inspiratory and expiratory times, 3

cyclic fluctuations in cerebral perfusion and blood pressure role in intracranial hemorrhage, 209

developmental outcome and mortality, at 5 years of age, 112

dopamine effects on heart function and blood pressure, hypotension, 136

EEG suppression after augmented breaths during apnea, 358

effects of in utero heavy metal exposure, maternal hair analysis, 189

endothelin 1-21 plasma levels, 143

family structure and stability impact on developmental outcome, 85

functional residual capacity measurement, helium/oxygen washout gas, 278

glycerol role in glucose production during first postnatal day, 225

head elevated prone position during nursing effects on incidence of apnea, 37

incidence of ischemic-hemorrhagic brain lesions, 51

increased plasma cGMP in hypotension, 137

intracerebral hemorrhage, cerebral blood flow disturbances, 25

with IRDS, PAF in causing complement activation, 36

lung function testing, in upper airway obstruction and flexible bronchoscopy, 5

mechanically ventilated, PEEP role in maintaining functional residual capacity, 229

nutrient balance, partially hydrolyzed whey formula, 52

outcome assessment by telephone interview, 214

patient triggered ventilation, trigger delay time, 131

periventricular flares role in predicting neurodevelopmental outcome, 220

pharmacokinetics and dynamics of rectally administered acetaminophen, 130

phototherapy effects on hemodynamics, 22

physiological variables effects on mean peak cerebral blood flow velocity during mechanical ventilation, 182

posterior corpus callosum damage, effects on cognitive processing deficits, at eight years of age, 107

qualitative assessment of early walking, 84

qualitative evaluation of spontaneous movement, 213

RDS, cardiac function and hypotension, 247

respiratory distress syndrome, bronchoalveolar lavage determination of macrophage infiltration, 171

respiratory distress syndrome, surfactant properties inhibition, by proteins, 80 sex differences in cerebral blood flow, 13

T lymphocyte differentiation, 377

tracheal interleukin-8 as predictor of chronic lung disease, 153

urogenital mycoplasma in development of chronic lung disease, 100

ventilated, respiratory distress syndrome, plasma protein activation, gestational age effects on, rabbits, 35

whole-body composition assessment, dual X-ray absorptiometry, 188

pulmonary function testing and respiratory mechanics, bronchiolitis, 291

RDS, interleukin-8 levels in bronchoalveolar lavage fluid, 185

retinopathy, $\beta$-sympathomimetics administered antenatally, 160

SIDS

prenatal exposure to cigarette smoke importance as risk factor for, 356

virological and clinical comparisons of respiratory tract viruses, 349

small-for-gestational age

after intrauterine growth retardation, cardiorespiratory profile, 272

microdialysis, determining metabolic adaptation, 98

preterm, developmental outcomes and mortality, at 5 years of age, 112

in utero heavy metal exposure effects, maternal hair analysis, 189

stridor, fiberobronchoscopic examination, 288

very low birth weight

adaptive response to indwelling nasogastric tube, 204

antenatal glucocorticoid administration, outcome at 5 years of age, 236

bone mineral content and body composition analysis, 122

cognitive skills and educational attainment at 8 years of age, 174

delayed motor function at 8 years of age, 173

indirect calorimetry versus ${ }^{2} \mathrm{H}^{18} \mathrm{O}$ methods of determining energy expenditure, 96

metabolic and energy balance, small and appropriate for gestational age, fed fortified human milk, 187

respiratory failure, congenital bacterial infection epidemiology and microbiology, 336

role, ketoconazole, treating fungal infections, gastric $\mathrm{pH}$ effects on absorption, 9

very preterm, clinical outcome after thyroxine administration, 250

vitamin $\mathrm{D}$ deficiency rickets, Gs-unit activity in, 146

water and hyaluronan concentration in lung, death within first day after birth, 205

whole blood microassay for immunophenotyping lymphocyte subpopulations, 245

Infection

acute, as cause of anemia, infancy and childhood, 77

adenovirus, nosocomial transmission of, neonates, 200

bacterial, amoxicillin treatment and pharmacokinetics, preterm infant, 10

Candida and Torulopsis, monocyte-stimulating capacity, infants, 97

Coxsackie virus, chronic form, children with IDDM, 113

early onset, complement activation during 


\section{SUBJECT INDEX TO ABSTRACTS}

first hours of life as indicator of, preterm infants, 257

fibronectin concentrations during, and correlation with immunoglobulin administration, low birth weight infants, 379

fungal, VLBW infants, ketoconazole treatment for, and gastric $\mathrm{pH}$ effects on, 9

Infectious disease, relation to development of Inhaler allergy, infants, 235

metered dose, salbutamol distribution, during mechanical ventilation, 109

pressurized metered dose, asthmatic children, holding chamber for treatment, 264

Inspiratory flow, effects, respiratory mechanics, during mechanical ventilation, neonates, 124

Insulin

resistance, inherited, early manifestation as transient neonatal diabetes, intrauterine growth retardation effects on, 208

role, factors in fetal overgrowth in diabetic pregnancy, 166

Insulin-glucose relationship, immunoradiometric assay in determining, neonate, 93

Insulin-like growth factor, trophoblastic receptors for, factors in fetal over-

Intelligence growth in diabetic pregnancy, 166

outcome, persistent hyperphenylalaninemia, and cranial MRI findings, 252

short-stature children, after intrauterine growth retardation, 121

Intensive care unit

neonatal

computerized trend monitoring in, outcome study, neonate, 155

genital mycoplasmas colonization, 347

nosocomial viral infection impact in, 200

pediatric

assessing performance, 362

epidemiology of adult respiratory distress syndrome in children, 363

management of asthma, children, 359

Interatrial left to right shunt, transient, echocardiographic studies, infants, 147

$\delta$-Interferon, concentration, tuberculosis meningitis, children, 334

Interhemispheric control, motor tests for determination of, cognitive processing deficits, preterm infants at 8 years of age, 107

Interleukin-2, dexamethasone inhibiting effects on, neonate, 105

Interleukin-6, levels in cerebrospinal fluid, patients with bacterial meningitis, 339

Interleukin-8

concentration, tuberculosis meningitis, children, 334

levels, bronchoalveolar lavage fluid, infants with RDS, 185

tracheal, as predictor of chronic lung disease, preterm infant, 153

Intestine, developing, xanthine oxidase activity and immunoreactive enzyme protein relation in, 129

Intracranial lesions, hypoxic ischemic encephalopathy, ultrasound and autopsy correlation, 244

Intrauterine growth retardation. see Growth, retardation, intrauterine

IRDS. see Respiratory distress syndrome, idiopathic

Iron deficiency, serum transferrin levels as indicator of, adolescent males, 11

homeostasis, resistance to oxidative hepatic injury, rats, 246

in infant cereals, hydroxyl radical formation, vitamin $C$ enhancement of, 7

release in erythrocytes, in neonatal oxidative hemolysis, 39

Ischemia

forearm oxygenation during, near infrared spectroscopy and $\mathrm{pO}_{2}$ histography analysis, 139

hemodynamics, cortical impedance and neuronal loss relationship after, fetal sheep, 149

near infrared spectroscopy measurement of oxidized cytochrome $\mathrm{aa}_{3}$ cerebral concentration after, 148

neonatal, influence of, in parietal cortex, rats, 48

Ischemia-reperfusion, xanthine oxidase role in tissue injury after, neonate, 201

Ischemic-hemorrhagic brain lesions

correlation between cerebral visual impairment, neurodevelopmental outcome, and MRI, neonates, 60

incidence of, preterm infants, 51

Isobaric conditions, changes in, microplethysmography measurement, 300

Isoniazide, inducing superoxide production in monocytes, 157

Jacket pressure, initiating Hering-Breuer de-

Jaundice flationary reflex, infants, 90

ceruloplasmin concentration and carboxyhemoglobin relationship, newborn infant, 53

neonatal, screening for glucose-6-phosphate dehydrogenase deficiency, 104

Ketoconazole, treating fungal infections, and gastric $\mathrm{pH}$ effects on absorption, VLBW infants, 9

Kidney

biopsy, determining $\mathrm{C}_{5 \mathrm{~b}-9}$ deposition in glomerular disease, children, 175

transplantation, bone mineral density after, children, 63

ultrasound, reliability of detecting vesicoureteral reflux, infants and children with urinary tract infection, 211

vascular responses in, angiotensin II and nitric oxide interactions, rabbit, 260

Kwashiorkor syndrome, leukotrienes in protein energy malnutrition, 151

Labor

association with increased phagocyte function during, 38

fetal cerebral oxygen saturation measurement during, predicting acid-base state at delivery, 6

Lactate, cerebral, after hypoxia-ischemia, newborn piglet, 134

Lactose intolerance, yogurt role in diet, children and adolescents, 196

Langerhans cells, histiocytosis, skin lesions in, children, 391

Laryngeal chemoreflex apnea, naloxone treatment for, piglet, 221

Laser

pulsed dye, treatment for port-wine stains, 395

semiconductor, treatment of chronic gastritis, children, 194

LBW. see Infant, low birth weight

Leishmaniasis, visceral, clinical and laboratory features, in Pakistani children, 341
Leucomalacia, cystic, cerebral metabolic abnormalities in, ' $\mathrm{H}-\mathrm{MR}$ spectroscopy, infant, 81

Leukemia

acute lymphoblastic

diagnosis of secondary leukemia in children with, 20

serum transferrin receptor and erythropoietin role as indicators of erythropoiesis, children, 110

hypertrophic osteoarthropathy in, children, 374

precursor B-acute lymphoblastic, detection of $\mathrm{T}$ cell receptor $-\delta$ rearrangements, 233

Leukocytes

activation, PAF and activated complement causing, preterm infants with IRDS, 36

neonatal, glucocorticoid sensitivity, 105

polymorphonuclear

levels, evaluations in gastric aspirate, critically ill neonates, 226

role, determining vitamin $\mathrm{E}$ nutritional status, infants and children, 103

Life threatening episodes

acute, hospitalization for, decreased plasma beta endorphins after treatment for gastro-esophageal reflux, infants, 352

apparent, high surface tension of lung surfactant, infants, 355

Lipid

peroxidation activity, in erythrocytes, ecological zone variations effects on, neonates, 207

tolerance, parenteral nutrition, low birth weight infants. see Infants, low birth weight

Lipid A, erythrocyte protection against, umbilical cord blood analysis, neonate, 193

Liver

developing, xanthine oxidase activity and immunoreactive enzyme protein relation in, 129

disease, measuring function, comparison study, children, 31

function, tests and ${ }^{13} \mathrm{C}$-phenylalanine breath test for measuring, comparison study, 31

gluconeogenesis, TNF- $\alpha$ in regulating, 256 immunophenotype, fetus, 222

injury, oxidative, iron chelates, rats, 246

Loratadin, effects, early and late asthmatic reaction, guinea pig, 273

Lung. see also under Pulmonary

damage, chronic, bronchoalveolar lavage role, diagnosis and prognosis, ventilated neonate, 295

development

after prenatal hormonal therapy, congenital diaphragmatic hernia, 135

early, perturbation by nitrofen exposure, rat, 265

disease

eosinophil cationic protein and myeloperoxidase levels in, children, 322

infants, synchronized and conventional intermittent ventilation, comparison study, 23

interleukin-8 role in pulmonary inflammation, neonate, 319

severe, dexamethasone treatment association with low triiodothyronine concentrations, ELBW infants, 66

surfactant activity from tracheo-bronchial material, 290 
tracheal interleukin-8 as predictor of preterm infants, 153

urogenital mycoplasmas role in development of, preterm infant, 100

fibroblasts, effects on hyaluronan synthesis, and role of surfactant and $\mathrm{N}$-acefunction ylcysteine in stimulating, 102

changes in, during bronchial provocation testing, asthmatic children, 117

healthy adolescent boys, outdoor air pollution effects, 320

influence on success of patient triggered ventilation, infant, 276

intravenous antibiotics effects, cystic fibrosis patients, 55

function testing during upper airway obstruction, and flexible bronchoscopy, preterm and term infant, 5

infants with bronchiolitis, 291

results of, atopic and nonatopic Estonian school age children, 327

short stature children, 305

histopathology, neonate receiving inhaled nitric oxide, 168

hyaluronan concentration, role of surfactant and $\mathrm{N}$-acetylcysteine in stimulating, 102

immaturity, biochemical, after congenital diaphragmatic hernia, neonate, 234

injury

hyperoxic, surfactant effects on monocytes and neutrophils during, 108

oxygen free radical measurement, superoxide dismutase and vitamin A effects, rabbit, 230

mechanics, congenital diaphragmatic hernia, neonates and infants, 180

suppurations, chronic, Streptococcus pneumoniae $\mathrm{IgG}$ subclasses and antibodies, in immunodeficient children, 326

water and hyaluronan concentration, infants which died in 1st day after birth, 205

Lupus, neonatal, SS-A antibodies in children, 373

Lymphocytes

lifespan length, children versus adult, HIV biological relevance, 351

$\mathrm{T}$, differentiation, preterm infants, 377

Lymphoma, cutaneous malignant, B-cell, infant, case study, 375

Macrophage infiltration, role of bronchoalveolar lavage in determining, respiratory distress syndrome, preterm infants, 171

Magnetic resonance imaging. see also Imaging

correlation with cerebral visual impairment and neurodevelopmental outcome, hemorrhagic-ischemic brain lesions, neonate, 60

cranial, persistent hyperphenylalaninemia, and intelligence outcome, 252

Magnetic resonance spectroscopy. see also under Spectroscopy

${ }^{13} \mathrm{C}$, adipose tissue fat composition measurement, infants, 91

${ }^{1} \mathrm{H}$, brain, measurement of water compartments and detection within myelin layers, 69

${ }^{31} \mathrm{P}$, determining severity of hypoxia-ischemia, newborn piglet, 158

proton, high spin-spin relaxation times after hypoxia-ischemia, newborn piglets, 42 role, clarifying pathogenesis of neurological abnormalities in galactosemia, 163

Malabsorption, carbohydrate and fat, after bowel resection, neonate, 126

Malnutrition

children, plasma free carnitine levels in, 227

and growth failure, children with inflammatory bowel disease, 30

mucosal infection susceptibility, cystic fibrosis, lung damage progression, 308

protein energy, leukotrienes, 151

Mastocytosis, N-methylhistamine excretion in urine role in diagnosing, 394

Maternal diet, influence on polychlorinated biphenyls, dibenzodioxins and -furans, in milk, 190

Maternal perception, of behavior of child, chronic atopic eczema, 64

Maternal transmission of HIV to child, influence of parity on. see Human immunodeficiency virus

Maxillofacial surgery, effects on children with obstructive sleep apnea, 94

Measles

vaccination, strategies for, monkey. see also under Vaccination

virus, cytotoxic $\mathrm{T}$ cell and IgA responses, vaccinated high school children, 332

Mechanical fragility, erythrocytes, infants, 198

Meconium, analysis

determining substance abuse during pregnancy, 183

as marker of fetal exposure to alcohol, 184

Medical ethics

bone marrow transplantation in children, and medico-legal concerns, 384

related to separation of conjoined twins,

Medical practice, general

acute otitis media, incidence, management and follow up, 346

difficulties diagnosing meningitis, children, 345

occurrence and treatment of impetigo, children, 397

Meningitis

bacterial and aseptic, interleukin- 6 levels in cerebrospinal fluid, 339

difficulties diagnosing in general practice, 345

tuberculosis

cerebrospinal fluid, $\delta$-interferon, TNF- $\alpha$, and interleukin- 8 concentrations, children, 334

evaluation of symptoms, clinical features and chest radiography features, children, 344

Meningococcal septic shock, cutaneous lesions and complications in acute meningococcaemia, in children, 396

Metabolic adaptation, microdialysis role in determining, small-for-gestational age infants, 98

Metabolic control, risk factor for color vision impairment, IDDM children, 132

Metabolic investigation, thymine-uraciluria, 92

Metabolic response, to exercise, lambs with aortopulmonary shunt, 16

Metal exposure, heavy, maternal hair analysis, in utero, risks of prematurity and small-for-gestational age infants, 189

Methacholine

bronchial provocation test, measuring serum levels of eosinophil cationic protein, bronchial hyperreactivity, children, 310

dose-response curves, before and during salmeterol treatment, asthmatic children, 302

provocation test, results, atopic and nonatopic Estonian school age children 327

$\mathrm{N}$-Methylhistamine excretion, in urine, role in diagnosing mastocytosis, 394

Microassay, whole blood, immunophenotyping infant and neonate lymphocyte subpopulations, 245

Microcirculation, impaired, immature neutrophil, neonates, 199

Microdialysis, determining, metabolic adaptation, small-for-gestational age infants, 98

Microplethysmography, measuring isobaric airway contraction, 300

Migraine, abdominal, recurrent, prevalence

Milk of, children, 306

dioxin and polychlorinated biphenyl levels in, effects on fetal neurodevelopment and relation to living area, 114

fortified human, metabolic and energy balance in small- and appropriate-forgestational age VLBW infants, 187

intolerance, yogurt role in diet, children and adolescents, 196

polychlorinated biphenyls, dibenzodioxins and -furans in, maternal diet influence on levels, 190

Molecular analysis, $\mathrm{Rb}-1$ segregation in families of children with retinoblastoma early diagnosis, 116

Molybdenum, and copper metabolism interrelationship, preterm infants, 210

Monocytes

stimulating capacity of Candida and Torulopsis species, infants, 97

superoxide production in, role of isoniazide, 157

surfactant effects, in hyperoxic lung injury, 108

Mortality

computerized trend monitoring in NICU effects on, outcome study. see Neonatal intensive care unit

prolonged ventilation as indicator of poor prognosis, bronchopulmonary dysplasia, infant, 303

rates

onset, IDDM, children and adolescents, 239

small-for-gestational age preterm infants, at 5 years of age, 112

Motor behavior, dexamethasone effects on, preterm infant with bronchopulmonary dysplasia, 28

Motor function, delayed, VLBW infants at 8 years of age, 173

Motor skill, development, early treated phenylketonuria, children, 191

Movement, spontaneous, qualitative evaluation of, preterm infants, 213

MRI. see Magnetic resonance imaging

MRS. see Magnetic resonance spectroscopy

Mycoplasma

genital, colonization of neonates in intensive care, 347

urogenital, development of chronic lung disease, preterm infant, 100

Mycoplasma hominis, determination of colonization of respiratory tract, neonates, 347

Mycoplasma pneumoniae, PCR role in de- 
tecting, lower respiratory tract infection, children, 337

Myelodysplastic syndrome, hypertrophic osteoarthropathy in childhood leukemia association, 374

Myocardial function, $\alpha$ - and $\beta$-adrenoceptor effects on, 26

Myoclonic jerks, role of thymine-uraciluria, 92

Nasal membrane potential difference, inhaled sodium channel inhibitors, cystic fibrosis mice, 74

Nasogastric tube, indwelling, adaptive response to, VLBW infant, 204

Nebulizer

jet, maintenance, bacterial contamination, and performance analysis, asthmatic children, 266

jet and ultrasonic, salbutamol distribution, during mechanical ventilation, 109

Neonate. see also Infant

absorptive capacity of bowel after resection, 126

adenovirus infection, nosocomial transmission, 200

arterial thrombolysis, recombinant tissue plasminogen activator role as treatment, 165

asphyxiated

at birth, iron-induced oxidative stress and reperfusion injury after, 58

necrotizing enterocolitis in, platelet-activating factor protective effects, piglet, 1

and reventilation effects, dopamine release and cortical oxygen pressure, piglet, 79

bisferiens pressure peaks in radial wave artery, as indicator of patent ductus arteriosus, 72

blood flow velocity measurements, superior mesenteric artery and renal artery, interobserver reliability, 253

blood pressure effects of surfactant replacement therapy, piglet, 162

cardiac and cerebral performance during high frequency oscillation, 178

cerebral blood flow and cerebral blood volume, near-infrared spectrophotometry role in investigating, 34

chronic lung disease, interleukin- 8 role in pulmonary inflammation, 319

clinical significance of testing for adherence, in coagulase negative Staphylococci, 361

computerized trend monitoring in NICU, outcome study, 155

congenital diaphragmatic hernia

biochemical lung immaturity, 234

lung volume and mechanics, 180

critically ill

accuracy of oscillometric blood pressure measurement, 73

arterial blood lactate, determining prognosis, 57

bacterial colonization and polymorphonuclear leukocyte levels, evaluation in gastric aspirate, 226

cytokine serum levels and superoxide anion generation, during peripartum, 38

fetal hypoxia, differentiation between acute and prolonged, twins, 142

heart rate modulation, baroreceptor reflex, 212

hemorrhagic-ischemic brain lesions, correlation between cerebral visual im- pairment, neurodevelopmental outcome, and MRI, 60

hypoxia, cerebral nitric oxide synthetase activity after, piglet, 82

immature neutrophil role in impaired microcirculation, 199

insulin-glucose relationship, immunoradiometric assay role in determining, 93

intensity of hypoxia effects on biochemical outcome, rats, 49

iron release in erythrocytes, evaluating risk of oxygen radical toxicity, 39

ischemia-reperfusion, xanthine oxidase role in tissue injury after, 201

lipid peroxidation activity in erythrocytes, ecological zone variations effects on, 207

lung histopathology, during inhaled nitric oxide, 168

mechanically ventilated

inspiratory flow rates effects on respiratory mechanics, 124

measurement of respiratory mechanics during, 287

near infrared spectroscopy, ferrite beads in eliminating electromagnetic interference during, 140

neutropenia, recombinant human granulocyte colony stimulating factor treatment for, 19

portal vein thrombosis, protein $\mathrm{C}$ deficiency role in, 164

RDS and pulmonary hypertension, nitric oxide, improving oxygenation, 4

receptors for phagocytosis and adhesion on neutrophil granulocytes, 65

refractory hypoxemia, bronchopulmonary effects of inhaled nitric oxide, 197

respiratory distress syndrome. see Respiratory distress syndrome

screening, glucose-6-phosphate dehydrogenase deficiency, 104

severe perinatal asphyxia, serum uric acid as index for, 259

surfactant replacement therapy and variation in intratissue $\mathrm{PO}_{2}$ relation, in surfactant deficiency, piglets, 99

thrombocytopenia, assessment of circulating megakaryocyte precursors in cord blood, 172

total body water and weight assessment, using bioelectrical impedance analysis, 161

transcranial Doppler sonography, safety guidelines, 101

transient foramen ovale incompetence, 147

urinary endothelin- 1 excretion, after furosemide administration, 223

ventilated

alveolar-arterial oxygen difference and ratio, 71

bronchoalveolar lavage, diagnosis and prognosis, chronic lung damage, 295

whole blood microassay for immunophenotyping lymphocyte subpopulations, 245

Neurodevelopment

after early treated phenylketonuria, children, 191

fetal, effects of dioxin and polychlorinated biphenyl levels in mother, and relation to living area, 114

outcome

hemorrhagic-ischemic brain lesions, neonate, correlation with cerebral visual impairment and MRI, 60 periventricular flares in predicting, preterm infants, 220

persistent pulmonary hypertension, risks of transport for ECMO versus conventional treatment, infant, 86

predictors of, ELBW infants at 5 years of age, 243

poor prognosis, prolonged ventilation as indicator of, bronchopulmonary dysplasia, infant, 303

prenatal exposure to coumarins, at $8-10$ years of age, 237

Neurological assessment, qualitative evaluation of spontaneous movement, visual Gestalt-perception, preterm infant, 213

Neutropenia, neonatal, recombinant human granulocyte colony-stimulating factor treatment, 19

Neutrophil

elastase, inhibition in sputum, cystic fibrosis patients, leukoprotease inhibitor 297

granulocytes, receptors for phagocytosis and adhesion expression, neonate, 65

immature, decreased deformability, impaired microcirculation, 199

surfactant effects, in hyperoxic lung injury, 108

NICU. see Intensive care unit, neonatal

Nitric oxide

and angiotensin II interaction, vascular responses in kidney, 260

inhaled

apparatus for application and monitoring, 177

bronchopulmonary effects of, refractory hypoxemia, neonate, 197

effects, pulmonary hypertension developed after cardiac surgery, infants, 360 effects on hemodynamics, cerebral activity and antioxidant status, lamb, 133

and exogenous surfactant, treatment for acute respiratory failure, rabbits, 78

lung histopathology, neonate, 168

preterm infants with bronchopulmonary dysplasia, 169

oxygenation improvement, neonates with RDS and pulmonary hypertension, 4 synthetase activity, cerebral, after hypoxia, newborn piglet, 82

Nitrofen, early lung development, rat, 265

NMDA receptor, glutamate antagonist role, reducing cerebral injury after stroke, 83

Nosocomial transmission, adenovirus infection, neonate, 200

Nursing, apnea during, head elevated prone position effects on, infants, 37

Nutrient balance, partially hydrolyzed whey formula, preterm infants, 52

Nutrition

assessment, by TOBEC and anthropometry, infants, 33

effects, effectiveness of recombinant human erythropoietin treatment, preterm infant with anemia, 17

energy expenditure calculation, estimating $\mathrm{CO}_{2}$ production, 15

iron-fortified infant cereal, vitamin $\mathrm{C}$ in hydroxyl radical formation, 7

needs, VLBW infants, indirect calorimetry versus ${ }^{2} \mathrm{H}^{18} \mathrm{O}$ methods of determining energy expenditure, 96

parenteral, low birth weight infants, lipid tolerance levels, 43

vitamin $E$ evaluation, infants and children, 103 
Nutritional challenge, relation to development of allergy, infants, 235

Obesity, deuterium dilution, measuring body composition changes during weight reduction, children, 70

Oscillation, high frequency. see Ventilation, high frequency oscillatory

Oscillatory pressure transients, after flow interruption, asthmatic children during bronchial challenge, 117

Oscillometric blood pressure, accuracy of measurement, critically ill neonates, 73

Osteoarthropathy, hypertrophic, in children with leukemia, 374

Otitis media, acute, incidence, management and follow up, in general practice, 346

Oxidant stress, surfactant-antioxidant liposomes, protecting against, preterm rabbits, 248

Oxidative stress, fetal birth-associated, antioxidant administration rat, 238

Oxime therapy, effects, carbamate poisoning, infants, 366

Oxygen

alveolar-arterial, difference and ratio, ventilated neonates, 71

free radicals, measurement, superoxide dismutase and vitamin A effects on, lung injury, rabbit, 230

pressure, cortical, and dopamine release, asphyxia and reventilation effects on, newborn piglet, 79

radical toxicity, iron release in erythrocytes, evaluating risk of, neonate, 39

saturation

blood transfusion effects on, preterm infants, 367

cerebral, fetal, measurement during labor, predicting acid-base state at delivery, 6

therapy, and maturational differences, infants with bronchiolitis, 260

transport, impaired, anemia/hypovolemia as cause, after cardiac surgery, 370

Oxygenation

arterial, exogenous surfactant and nitric oxide as treatment for, rabbits, 78

cerebral, effects of $\mathrm{CO}_{2}$ changes during ECMO, piglet, 127

extracorporeal membrane

cerebral oxygenation and hemodynamic alterations due to opening of the bypass bridge during, piglet, 128

effects of $\mathrm{CO}_{2}$ changes during, piglet, 127

risks for transport and developmental outcome versus conventional treatment, infants with persistent pulmonary hypertension, 86

forearm, near infrared spectroscopy and $\mathrm{pO}_{2}$ histography, during ischemia, 139

nitric oxide, neonates with RDS and pulmonary hypertension, 4

surfactant instillation methods, effectiveness of, preterm infants, 206

PAF. see Platelet-activating factor

Pain, treatment, preterm infants, pharmacokinetics and dynamics of acetaminophen, 130

Palatine tonsils, monitoring airborn and alimentary antigens in, SIDS cases evaluation, 357

Pancreas, size, children and adolescents with IDDM, ultrasound evaluation, 241

Paracetamol, and ibuprofen, treatment for febrile seizures, 62
Parietal cortex, influence of hypoxia and ischemia, neonatal rats, 48

Parity, influence on mother-to-child HIV transmission, 106

Paroxysms, vagal reflex strength with, children, 89

Patent ductus arteriosus, bisferiens pressure peaks in neonatal radial artery wave as indicator of, 72

Paternity, glucose-6-phosphate dehydrogenase deficiency, neonate, 104

PCR. see Polymerase chain reaction

Peak flow meter, simple cost effective, pediatric asthma patients, 67

Pediatricians, difficulties relating diagnoses to children, 123

Pediatrics. see Children

Pediatric transport

quality assurance scores for, 141

risks of, for ECMO, persistent pulmonary hypertension, versus conventional treatment, and developmental outcome, infants, 86

PEEP. see Positive end expiratory pressure

Periventricular flares, predicting neurodevelopmental outcome, preterm infant, 220

Peroxisomes, dicarboxylic acid $\beta$-oxidation in, Zellweger syndrome patients, 152

Phagocytosis, receptors for, neutrophil granulocytes, neonates, 65

Pharmacokinetics, ceftazidime, preterm infants, 329

Phenobarbital, causing behavior disturbances, children, 380

Phenylalanine, cerebral concentrations, phenylketonuria patients, ${ }^{1} \mathrm{H}$ MRS determination, 192

Phenylketonuria

cerebral phenylalanine concentrations, ${ }^{1} \mathrm{H}$ MRS determination, 192

early treated, fine motor skill development, children, 191

plasma phenyllactate evaluation, 95

psychiatric disorders in adults with, 386

Phenyllactate, evaluation of, in phenylketonuria, 95

Phototherapy, effects, hemodynamics, preterm infants, 22

Physiological variables, effects, mean peak cerebral blood flow velocity during mechanical ventilation, preterm infants, 182

Physiotherapy

chest, gastroesophageal reflux symptoms during, positive expiratory pressure in avoiding, 267

cystic fibrosis infants, effects of position on gastro-esophageal reflux, 4

PICU. see Intensive care unit, pediatric

Placebo-phenomenon, phenomenological approach to the child as a solution to the enigma of, 388

Plasma

dioxin and polychlorinated biphenyl levels in, effects on fetal neurodevelopment and relation to living area, 114

fibronectin, concentrations, during infection and correlation with immunoglobulin administration, low birth weight infant, 379

free carnitine, levels, malnourished children, 227

lactate, variables influencing level of, indicator of anemia, piglet, 87

Plasminogen activator, recombinant tissue, treatment of arterial thrombolysis, neonate, 165
Platelet-activating factor

protective effects, necrotizing enterocolitis, in asphyxiated newborn piglet, 1

role, causing complement activation, preterm infants with IRDS, 36

Plethysmography, respiratory inductance, measurement of bronchial obstruction, asthmatic children, 262

Pneumonia

acute lobar/segmental, radiographic clearing relation to early treatment, children, 269

diagnosing, differentiation with pulmonary tuberculosis, children, 274

roentgenogram characterization of round shadows, in children, 268

role, as cause of anemia, infants and children, 77

Pneumothorax, bilateral, hyperinsulinism aggravation, postasphyxial glucose administration, piglet, 228

Polychlorinated biphenyl

effects on thyroid hormone levels, pregnant women and their infants, 115

levels in mother, effects on fetal neurodevelopment and relation to living area, 114

Polygraphic recording, determining extent of obstructive sleep apnea, children, 94

Polymerase chain reaction,

detecting Mycoplasma pneumoniae, in childhood lower respiratory tract infections, 337

prenatal diagnosis hemophilia, 44, Xlinked lymphoproliferative disease, 324

Port-wine stains, treatment with pulsed dye laser, 395

Positioning, head elevated prone, effects on apnea during nursing, preterm infants, 37

Positive end-expiratory pressure

maintaining functional residual capacity, mechanically ventilated preterm infants, 229 ,

therapy, avoiding gastro-esophageal reflux symptoms during chest physiotherapy, cystic fibrosis children and adolescents, 267

Posterior corpus callosum, damage, effects on cognitive processing deficits, preterm infants at 8 years of age, 107

Postural drainage, inducing gastro-esophageal reflux symptoms, during chest physiotherapy, cystic fibrosis children and adolescents, 267

Potential difference, nasal membrane, inhaled sodium channel inhibitors, cystic fibrosis mice, 74

Pregnancy

alcohol use during, meconium analysis role in determining, 184

amphetamine abuse during, follow-up of children after 14 years, 61

diabetic, factor for fetal overgrowth in, 166

effects of dioxin and polychlorinated biphenyl on thyroid hormone during, 115

heavy metal exposure during, maternal hair analysis, risks of prematurity and small-for-gestational age infants, 189

substance abuse during, maternal hair and meconium analysis role in determining, 183

Prematurity, risks, in utero heavy metal exposure, maternal hair analysis, 189

Prenatal diagnosis

hemophilia, chorionic villus sampling and PCR, 44 
$\mathrm{X}$-linked lymphoproliferative disease, polymerase chain reaction, 324

Primary immune deficiencies, and autoimmunity, prevalence of different types, 313

Prognosis, poor, prolonged ventilation as indicator of, bronchopulmonary dysplasia, infant, 303

Prone sleeping position, effects on incidence of SIDS, 348

Protein C, deficiency, role in causing portal vein thrombosis, neonate, 164

Pseudohypoparathyroidism, Gs-unit activity in, 145

Pseudomonas aeruginosa, chronic bronchitis, cystic fibrosis patients, 55

Pseudoseizures, differentiation with epilepsy, diagnostic procedure, 385

Psychiatric disorders, adults with phenylketonuria, 386

Psychological function, sleep disturbance effects in, epileptic children, 387

Psychological outcome, extremely low birth weight infants, two-year outcome, 50

Psychosocial factors, childhood asthma, 277

Psychosocial functioning, children with juvenile chronic arthritis, 383

Psychotherapy, treatment of asthmatic children with emotional disorders, 251

Puberty, precocious, calcium metabolism after gonadotropin-releasing hormone treatment, children, 240

Pulmonary function testing, during upper airway obstruction, and flexible bronchoscopy, preterm and term infant, 5

Pulmonary diffusing capacity, reduced alveolar volume, children and adolescents, 218

Pulmonary tuberculosis, evaluation and diagnosis, children, 274

Pulse arrival time, evaluation, marker of blood pressure changes after heart surgery, infants and children, 371

Pulsed dye laser, treatment for port-wine stains, 395

QT interval, and heart rate during 1st year of life, SIDS association, 354

Quality

abstracts

assessment and objectivity, 156

structured versus unstructured, information content comparison, 154

of care, assessing performance of pediatric intensive care unit, 362

Quality assurance, scores for pediatric transport, 141

Radiography

acute lobar/segmental pneumonia, clearing of in relation to early treatment children, 269

characterization of round shadows, indicating pneumococcal pneumonia children, 268

chest

cystic fibrosis, scoring system, reliability of, 293

evaluation, tuberculosis, children, 344

lateral chest, diagnosing pulmonary tuberculosis, 330

Radioimmunoassay, measuring levels of bile acid concentrations, preterm infants with cholestasis, 202

RDS. see Respiratory distress syndrome

Reading skills, and cognitive development, VLBW infants at 8 years of age, 174

Reflex, Hering-Breuer deflationary, stand- ardization of, and factors initiating, infants, 90

Reflex activity, influence on success of patient triggered ventilation, infant, 276

Reflex anoxic seizures, vagal reflex association with, children, 89

Renal artery, blood flow velocity measurements, interobserver reliability, neonate, 253

Reperfusion injury, iron-induced oxidative stress in, after severe birth asphyxia, 58

Respiratory disease, curantil treatment effects, children, 296

Respiratory distress syndrome

adult, epidemiology of in children, 363

cardiac output and hypotension, preterm infants, 247

chronic lung disease development after, pulmonary inflammation after, 319

computer-controlled ventilation treatment, preterm infants, 3

idiopathic

complement activation, preterm infants, PAF and, 36

plasma protein activation, gestational age influence, preterm ventilated rabbits, 35

interleukin-8 levels in bronchoalveolar lavage fluid, infants, 185

macrophage infiltration and matrix disruption, bronchoalveolar lavage, preterm infants, 171

nitric oxide, improving oxygenation, neonate, 4

surfactant properties inhibition, by proteins, preterm infants, 80

surfactant replacement therapy, factors associated with response to, neonates, 59

Respiratory failure

acute, nitric oxide and exogenous surfactant as treatment, rabbits, 78

congenital bacterial infection, epidemiology and microbiology of, VLBW infants, 336

Respiratory infections, viral, direct immunofluorescence role in diagnosing, 343

Respiratory mechanics

infants with bronchiolitis, 29

measurement, during mechanical ventilation, neonates, 287

Respiratory problems

acute, children with, life-style and activity patterns comparison study, 8

prevalence in school age children, 298

Respiratory symptoms, prevalence, Estonian school age children, 316

Respiratory syncytial virus

autoreactive antibodies presence association with, 335

decay of maternally derived antibodies against, infants, 333

infection, influence on allergic sensitization, infants, 312

Respiratory tract

determination of colonization of Ureaplasma urealyticum and Mycoplasma hominis, neonate, 347

infection, polymerase chain reaction role detecting Mycoplasma pneumoniae, children, 337

infections, as cause of anemia, infants and children, 77

virus, SIDS victims, virological and clinical comparisons, 349

Retinoblastoma, molecular analysis of Rb-1 segregation in families of children with, early diagnosis and treatment, 116

Retinopathy, $\beta$-sympathomimetics administered antenatally, preterm infants, 160

Reventilation, and asphyxia effects, dopamine release and cortical oxygen pressure, newborn piglet, 79

Rhinitis, allergic

comparison study of assessment tests, children, 299

prevalence of, at four years of age, 314

Rhinolaryngoscopy, diagnosing vocal cord dysfunction, children, 120

Rickets, vitamin D deficiency, Gs-unit activity in, infants, 146

Salbutamol

clinical and functional response to, acute bronchiolitis, 275

distribution, comparison of methods, during mechanical ventilation, 109

effects, preventing exercise-induced asthma, children, 292

Salmeterol

inhaled, overnight protection for exerciseinduced asthma, children, 271

treatment, methacholine dose-response curves before and during, asthmatic children, 302

Salmonella typhi, multi-drug resistant, epidemiology of, Pakistani children, 342

Schonlein Henoch syndrome, von Willebrand factor and factor XIII determination in, children, 376

Scientific literature, abstracts, assessment and objectivity of, 156

Scleroderma, circumscribed, course of, children, 390

Seizure

febrile

ibuprofen and paracetamol treatment for, children, 62

risk factors for seizure recurrence, 181

thymine-uraciluria, 92

reflex anoxic, vagal reflex association with, children, 89

Serum transferrin receptor, indicator of erythropoiesis, children with acute lymphoblastic leukemia, 110

Short stature, children, lung function testing, 305

Shunt, aortopulmonary, metabolic response to exercise, lambs, 16

SIDS. see Sudden infant death syndrome

Sjogren's syndrome, SS-A antibodies in children, 373

Skin lesions

characterization of, children who survived fulminant meningococcal septic shock, 396

Langerhans cell histiocytosis, children, 391

Sleep

abnormal, psychological effects, childhood asthma, 304

apnea, obstructive, children with craniofacial anomalies, 94

disturbances

children with craniofacial abnormalities, 94

effects on psychological function, epileptic children, 387

position

effects on apnea, hypoxemia, and bradycardia, preterm infants, 118

prone, effects on incidence of SIDS, 348

problems, chronic atopic eczema influence on, children, 64 
Sn-protoporphyrin, effects, plasma bilirubin levels, rats, 14

Sobbing spasm, vagal reflex association with, children, 89

Social support, family structure and stability impact on developmental outcome, preterm infant, 85

Sodium channel inhibitors, nasal membrane potential difference, cystic fibrosis mice, 74

Sonography, transcranial Doppler, guidelines for safety, neonate, 101

Spasm, sobbing, vagal reflex association with, children, 89

Spectrophotometry

near-infrared, detecting increased blood oxygen content effects on cerebral blood volume, neonates, 34

role, measurement of fetal hemoglobin, term and preterm neonates, 364

Spectroscopy. see also specific types

carbon 13 magnetic resonance, adipose tissue fat composition measurement, infants, 91

${ }^{1} \mathrm{H}$ magnetic resonance

brain, measurement of water compartments and detection within myelin layers, 69

determining brain abnormalities after perinatal asphyxia, infant, 186

determining cerebral phenylalanine concentrations, phenylketonuria patients, 192

magnetic resonance

clarifying pathogenesis of neurological abnormalities in galactosemia, 163

demonstrating cerebral metabolic abnormalities, infants with cystic leucomalacia, 81

near infrared

analysis of forearm oxygenation, 139

measuring oxidized cytochrome $\mathrm{aa}_{3}$ cerebral concentration, after ischemia, 148

role of ferrite beads in eliminating electromagnetic interference during neonatal data collection, 140

near infrared absorption, cerebral venous saturation measurements, children and adolescents, 255

${ }^{31} \mathrm{P}$ magnetic resonance, determining severity of hypoxia-ischemia, newborn piglet, 158

proton magnetic resonance

high spin-spin relaxation times after hypoxia-ischemia, newborn piglets, 42

predicting outcome after perinatal asphyxia, 125

Spirometry, measuring pulmonary function, healthy male adolescents, 320

SS-A, antibodies, association with Sjogren's syndrome, subacute cutaneous lupus erythematosus and neonatal lupus, 373

Staphylococci, coagulase negative, clinical significance of adherence testing, neonates, 361

Steroid 21-hydroxylase, deficiency, recombination event causing deletion of gene CYP21, 56

Streptococcus pneumoniae

adhesion of, to human epithelial cells, 338

IgG subclasses and antibodies, in immunodeficient children with chronic lung suppurations, 326

resistant, epidemiology of, children, 340

Stridor, fiberobronchoscopic examination, infants, 288
Substance abuse

fetal exposure to, amphetamines, followup of children after 14 years, 61

during pregnancy

meconium analysis in determining fetal exposure to alcohol, 184

role, maternal hair and meconium analysis in determining, 183

Sudden infant death syndrome

heart rate variability association, 353

prenatal exposure to cigarette smoke importance as risk factor for, 356

prenatal exposure to cocaine, breathing patterns of infants, 203

prone sleeping position effects on incidence, 348

QT interval and heart rate during 1st year of life, 354

respiratory and cardiac control, small-forgestational age infants born after intrauterine growth retardation, 272

respiratory tract viruses in victims, virological and clinical comparisons, 349

Superior mesenteric artery, blood flow velocity measurements, interobserver reliability, neonate, 253

Superoxide dismutase, effects, lung injury, rabbit, 230

Superoxide production, in monocytes, role of isoniazide, 157

Surface tension, high, of lung surfactant, infants with apparent life threatening episodes, 355

Surfactant

and antioxidant liposomes, protecting against oxidant stress, preterm rabbits, 248

deficiency, surfactant replacement and variation in intratissue $\mathrm{PO}_{2}$ relation, newborn piglet, 99

effects, monocytes and neutrophils in hyperoxic lung injury, 108

exogenous, and nitric oxide, treatment for acute respiratory failure, rabbit, 78

lung, high surface tension, infants with ALTE. see Life threatening episodes, acute

phospholipid composition and saturation analysis, HPLC in, 263

properties inhibition, by proteins, preterm infant with RDS, 80

protein A, surfactant lipid endocytosis, 219

protein $C$, characterization of, 54

replacement therapy

blood pressure effects, newborn piglet, 162

response to, respiratory distress syndrome, neonate, 59

and variation in intratissue $\mathrm{PO}_{2}$ relation, in surfactant deficiency, newborn piglets, 99

role

NAP-2-induced neutrophil activation modulation, 369

stimulating lung hyaluronan synthesis, 102

tracheal infusion, effectiveness of, versus bolus instillation, rabbits, 206

Surgery. see also specific types

congenital heart disease, behavior and emotional outcome predictors, after surgery for congenital heart disease, children, 232

maxillofacial, effects on children with obstructive sleep apnea, 94

Surveillance, disease, British Paediatric Surveillance Unit, role, investigating rare childhood disorders, beneficial health effects resulting, 179

$\beta$-Sympathomimetics, administration during labor, causing retinopathy in preterm infants, 160

Syndrome. see specific types

Synovitis, transient, hip, prevalence and management, children, 242

Tachycardia, blood transfusion effects on preterm infants, 367

$\mathrm{T}$ cell receptor- $\delta$, detection of, in precursor B-acute lymphoblastic leukemia, 233

Tetanus, humoral immune responses, atopic and nonatopic children, 309

Thermodilution method, measurement of cardiac output, comparison with the Fick principle, children, 372

Thermoregulation, in skin blood flow, and heart rate variability, association with SIDS, infants, 350

Thrombocytopenia

after recombinant human granulocyte colony stimulating factor treatment for neonatal neutropenia, 19

megakaryocyte precursors in, neonate, 172

Thrombolysis, arterial, recombinant tissue plasminogen activator as treatment, neonate, 165

Thrombosis, portal vein, protein $\mathrm{C}$ deficiency in, neonate, 164

Thymine-uraciluria, metabolic investigation of, 92

Thymus, immunophenotype, fetus, 222

Thyroid hormone, dioxin and polychlorinated biphenyl effects on, pregnant women and their infants, 115

Thyroxine, administration of, clinical outcome, very preterm infants, 250

Tidal flow volume, changes in, lower airway disease, eosinophil cationic protein and myeloperoxidase, 289

Tinea capitis, epidemic occurrence in Rotterdam, 392

$\mathrm{T}$ lymphocyte, differentiation, preterm infants, 377

TOBEC. see Total body electrical conductivity

$\alpha$-Tocopherol blood cells, evaluating vitamin E nutritional status, infants and children, 103

Tonsil, palatine, monitoring airborn and alimentary antigens in, SIDS cases evaluation, 357

Torulopsis, and Candida species, monocytestimulating capacity, 97

Total body electrical conductivity

estimating fat-free mass and body fat, infants, 32

nutritional assessment, infants, 33

Tracheal bronchus, diagnosing, differentiation with pulmonary tuberculosis, children, 274

Transferrin, serum, increasing levels, indicator of iron deficiency or erythropoiesis, adolescent males, 11

Transplantation

bone marrow, in children, ethical and medico-legal concerns, 384

kidney, bone mineral density after, children, 63

Trauma, multiple, case review, children, 368

Triiodothyronine concentrations, dexamethasone treatment association, ELBW infants with hypotension or severe lung disease, 66

Trophoblastic receptors, factors in fetal overgrowth in diabetic pregnancy, 166 


\section{SUBJECT INDEX TO ABSTRACTS}

Tuberculosis

pulmonary

evaluation and diagnosis, children, 274

lateral chest radiograph role in diagnosing, children, 330

symptoms, clinical features and chest radiography features, children, 344

Tuberculosis meningitis, cerebrospinal fluid, $\delta$-interferon, TNF- $\alpha$, and interleukin8 concentrations, children, 334

Tumor, B cell, cutaneous malignant lymphoma, infant, case study, 375

Tumor necrosis factor- $\alpha$

concentration, tuberculosis meningitis, children, 334

production in MNC from synovial fluid, juvenile rheumatoid arthritis, 32

role, regulation of liver gluconeogenesis, rats, 256

Twins

conjoined, medical and ethical issues related to separation, 170

fetal hypoxia, differentiation between acute and prolonged, 142

monozygotic and dizygotic, genetic analysis umbilication cord blood, 315

Typhoid fever, multi-drug resistant Salmonella typhi development in, epidemiology, Pakistani children, 342

Ultrasound

evaluation, pancreas size, children and adolescents with IDDM, 241

evaluation of intracranial lesions in hypoxic ischemic encephalopathy, and autopsy correlation, infants, 244

periventricular flares evaluation, preterm infants, 220

renal, reliability of, detecting vesicoureteral reflux, infants and children with urinary tract infection, 211

role, detecting ischemic-hemorrhagic brain lesions, preterm infants, 51

Umbilical cord blood

analysis of erythrocytes for endotoxin protection, 193

assessment of circulating megakaryocyte precursors in, neonatal thrombocytopenia, 172

genetic analysis, monozygotic and dizygotic twins, 315

$\mathrm{T}$ lymphocyte detection in, preterm infants, 377

Ureaplasma urealyticum, determination of colonization of respiratory tract, neonates, 347

Uric acid, serum, as index for severe perinatal asphyxia, neonate, 259

Urinary cotinine, excretion, after passive exposure to cigarette smoke, children, 216

Urinary endothelin-1, excretion, after furosemide administration, neonate, 223

Urinary tract, infection as cause of anemia, infants and children, 77

vesicoureteral reflux, reliability of renal ultrasound for detecting, infants and children, 211

Urogenital mycoplasma, development of chronic lung disease, preterm infants, 100

Urticaria, prevalence of, at four years of age, 314

Vaccination. see also Immunization

measles, strategies for, monkey, 331

Vagal reflex, strength of, with paroxysmal events, children, 89

Valproate treatment, chronic, energy metabolism composition determination, using indirect calorimetry, children, 159

Vasodilator, effects, treatment for respiratory disease, children, 296

Ventilation

alveolar-arterial oxygen difference and ratio, neonates, 71

computer-controlled, preterm infants, using spontaneous inspiratory and expiratory times, 3

high frequency oscillatory, cardiac and cerebral performance during, neonate, 178

intermittent mandatory, synchronized and conventional, comparison study, infants with lung disease, 23

mechanical

apparatus for application and monitoring of inhaled nitric oxide, 177

bronchoalveolar lavage role, diagnosis and prognosis, chronic lung damage, neonate, 295

bronchopulmonary dysplasia, inhaled nitric oxide effects, preterm infants, 169

inspiratory flow effects on respiratory mechanics, neonates, 124

measurement of respiratory mechanics, neonate, 287

physiological variables effects on mean peak cerebral blood flow velocity during, preterm infants, 182

preterm infant, PEEP role in maintaining functional residual capacity, 229

salbutamol distribution, comparison of methods, 109

patient triggered

lung function and reflex activity influence on success of, infant, 276

trigger delay time, preterm infants, 131

prolonged, bronchopulmonary dysplasia, poor prognosis after, infants, 303

respiratory distress syndrome, plasma protein activation, gestational age influence, preterm rabbits, 35

Vesicoureteral reflux, reliability of detection with renal ultrasound, infants and children with urinary tract infection, 211

Vessels, cerebral and precerebral, anatomy of, newborn pig, and comparison with human, 88

Viral respiratory infections, direct immunofluorescence in diagnosing, 343

Virus. see specific types

Visceral Leishmaniasis, clinical and laboratory features, in Pakistani children, 341

Vision, impairment, color, poor metabolic control as risk factor for, IDDM children, 132

Vitamin A, effects, lung injury, rabbit, 230

Vitamin D

deficiency rickets, Gs-unit activity in, infants, 146

mediation by 1,25 dihydroxyvitamin D3 receptors, measurement, cord peripheral mononuclear cells, term infants, 167

Vitamin $\mathrm{E}$, nutritional status evaluation, infants and children, 103

VLBW. see Infant, very low birth weight

Vocal cord dysfunction, pediatric, rhinolaryngoscopy in diagnosing, 120

von Willebrand factor, determination of, in Schonlein Henoch syndrome, children, 376

Walking, qualitative assessment of early walking, preterm and full-term infants, 84

Water

content in lung, infants which died in 1st day after birth, newborn rabbits, 205

detection in brain, 'H MR-spectroscopy, 69

Weight

assessment, using bioelectrical impedance analysis, neonate, 161

body, assessment of, dual X-ray absorptiometry, preterm infants, 188

Weight loss

after acute diarrhea, effects of early resumption of feeding on infants, 176

children with cancer, megestrol effects on 12

Weight reduction, body composition changes during, obese children, deuterium dilution measurement, 70

Xanthine oxidase

activity, and immunoreactive enzyme protein, in developing liver and intestine, 129

gene expression, in developing human tissues, enzyme activity relation, neonate, 201

$\mathrm{X}$ chromosome, methylation pattern, females with low factor VIII:C level, 2

$\mathrm{X}$-linked lymphoproliferative disease, prenatal diagnosis, polymerase chain reaction role, 324

Yogurt, diet of lactose intolerant children and adolescents, 196

Zellweger syndrome, peroxisome in degradation of dicarboxylic acid, 152 